\title{
Causalidade, Contingência, Complexidade: o Futuro do Conceito de Risco
}

NAOMAR DE ALMEIDA-FILHO

DENISE COUTINHO •

\section{RESUMO}

Defendemos a tese de que, na atual fase de maturação do campo epidemiológico, uma reavaliação do conceito de risco é necessária. Inicialmente, discutimos os fundamentos das categorias causalidade e contingência a partir da obra de dois filósofos, Aristóteles e Pascal. Em segundo lugar, recuperando algumas reflexões anteriores sobre as bases lógicas do conceito de risco, discutimos criticamente sua adequação e eficácia explicativa frente ao objeto saúdedoença. Em terceiro lugar, apresentamos brevemente categorias e conceitos fundantes do paradigma da complexidade, capazes de dar conta dos fenômenos da emergência, não-linearidade e borrosidade relacionados aos novos objetos complexos e mutantes da saúde. Concluímos com alguns comentários e reflexões ainda preliminares sobre fundamentos, perspectivas e conseqüências da aplicação da modalidade "contingência" como alternativa à noção de determinação no campo da saúde, a fim de visualizar o futuro do conceito de risco para além da área temática (científica e tecnológica) da Epidemiologia contemporânea.

Palavras-chave: Risco; causalidade; contingência; complexidade; Aristóteles.

Recebido em: 03/03/2007.

Aprovado em: 15/03/2007. 


\section{Introdução}

A Epidemiologia, designada inicialmente como um "método" (desde MACMAHON; PUGH, 1970), hoje pode ser entendida como uma ciência que se baseia num tipo peculiar de aplicação setorial da lógica formal. Trata-se de um modo de raciocinar caracterizado por uma ontologia particular - baseada nas categorias de conjunto e de elementos - e por uma lógica operativa padronizada - que obedece a regras específicas de validação e de inferência -, o determinismo causalista. Nessa perspectiva, a ciência adere fortemente a uma epistemologia empiricista convencional.

Com o advento da chamada Epidemiologia moderna (ROTHMAN; GREENLAND, 1998), na década de 1980, a formalização do conceito de risco como probabilidade condicional de ocorrência de eventos de saúde-doença permitiu rigor teórico e capacidade preditiva nos campos de planificação e gestão em saúde. O conceito de risco havia sido originalmente proposto no campo da Epidemiologia como tradutor parcial de proposições causalistas (ou seja, risco como sucedâneo da noção de etiologia, em um referencial quasi-probabilístico). Apesar disso, em paralelo, o impacto de sua aplicação como operador prático de atos diagnósticos e terapêuticos nos campos clínicos tem sido grandemente reduzido. Atualmente superada por recentes demandas trazidas pelos avanços do conhecimento sobre processos patológicos, a abordagem desta forma peculiar de representação dos nexos entre processos e eventos relativos à saúde-doença na sociedade moderna necessita de um reexame crítico das suas bases lógicas e históricas.

Neste ensaio defendemos a tese de que, na atual fase de maturação do campo epidemiológico, uma reavaliação do conceito de risco é necessária. Inicialmente, discutimos os fundamentos das categorias causalidade e contingência a partir da obra de dois filósofos, Aristóteles e Pascal. Em segundo lugar, recuperando algumas reflexões anteriores sobre as bases lógicas do conceito de risco (ALMEIDA FILHO, 1992), revisamos criticamente sua adequação e eficácia explicativa frente ao objeto saúde-doença. Em terceiro lugar, apresentamos brevemente categorias e conceitos fundantes do paradigma da complexidade, capazes de dar conta dos fenômenos da emergência, nãolinearidade e borrosidade relacionados aos novos objetos complexos e mutantes da saúde. Concluímos com alguns comentários e reflexões ainda preliminares sobre fundamentos, perspectivas e consequiências da aplicação da modalidade "contingência" como alternativa à noção de determinação no campo da saúde, 
a fim de visualizar o futuro do conceito de risco para além da área temática (científica e tecnológica) da Epidemiologia contemporânea.

\section{Fundamentos lógicos da causalidade e da contingência}

Aristóteles (384-322 a.C.) trabalha com dois gêneros de filosofia: a filosofia prática, que compreende a Ética e a Política, e a filosofia teórica, que contém a Física e a Lógica, sendo esta última o meio de compreender todas as outras. A Lógica é tomada por Aristóteles como arte cuja finalidade seria distinguir a diferença entre o verossímil e o verdadeiro. Atento à "invenção", fornece "os tópicos e o método como se fossem multidão de proposições segundo as quais se pudessem achar argumentos prováveis - e não possíveis - para as questões argüidas" (ARISTÓTELES, 1985, p. 34). Todas essas questões são tratadas no Organon (ibid.), conjunto de seis livros sobre lógica, onde três registros do conhecimento humano são estudados: a Retórica, a Gramática e a Analítica.

Gerações de exegetas e analistas encontraram quatro teorias (ou tópicos) sistematizadas a partir do pensamento aristotélico: (1) teoria do Real; (2) teoria do Ser; (3) teoria dos Eventos; (4) teoria das Causas. A teoria aristotélica do Real repousa sobre duas categorias principais: Universal e Particular. A teoria do Ser compõe-se de três proposições sobre a existência dos entes na linguagem e no mundo que, posteriormente, foram reunidas como princípios da lógica formal: (i) princípio da identidade (o Ser é igual a si próprio: $\mathrm{A}=\mathrm{A}$ ); (ii) princípio da não-contradição (o Ser é diferente do que não é ele: $\mathrm{A} \# \neg \mathrm{A}$ ); (iii) princípio do terceiro excluído (o Ser é ou não é; verdadeiro ou falso: A é V ou F; A nunca pode ser, ao mesmo tempo, V e F). A teoria dos Eventos baseia-se na proposição de quatro categorias que vieram a ser conhecidas como os modais de Aristóteles: Possível, Impossível, Necessário e Contingente. Finalmente, a teoria das Causas, que introduziu uma tipologia bastante conhecida na metodologia científica: (i) Causa material; (ii) Causa final; (iii) Causa formal; (iv) Causa eficiente. A consistência geral do sistema filosófico aristotélico impede de se tratar cada uma dessas teorias como componentes isolados, requerendo uma articulação entre seus princípios, categorias e proposições.

Embora o senso comum atribua ao Universal uma vinculação com a totalidade, Aristóteles não o conceitua dessa maneira. Para ele, universal refere- 
se a "vários": "Universal é o que, sendo algo de uno, é apto por sua natureza para existir em vários [sujeitos]" (1985, p. 171). O particular designa "qualquer uno que se pode subordinar a algum universal", ou aquilo que não pode ser afirmado de vários (ibid., p. 128). Aristóteles ainda define que um sujeito pode ser tomado como universal, "o homem", e as proposições a este sujeito atribuídas não serem universais. Assim, "o homem é branco" não é uma proposição universal, ainda que se possa tomar o sujeito como tal. Paradoxalmente, nem mesmo quando o termo "todo" está indicado numa proposição há garantia de universalidade, pois "não é verdadeira nenhuma afirmação em que o universal é atribuído ao predicado universal, como ocorre na proposição todo o homem é todo animal" (p. 128).

O valor de verdade é uma atribuição e não está dado para nenhuma proposição. Nas proposições particulares (algum, ao menos um), há exemplos de opostos que podem ser simultaneamente verdadeiros: "algum homem é branco" e "algum homem não é branco", porque: "das proposições que, referentes ao universal, não são enunciadas universalmente, nunca se pode dizer que uma é verdadeira e outra falsa" (ARISTÓTELES, 1985, p. 131). Mesmo para proposições unas e singulares, Aristóteles adverte: caso um nome tenha mais de um significado (seja complexo, segundo ele), e caso seja referido a duas coisas, então, tanto a afirmação quanto a negação deixam de ser unas. Em conseqüência, duas contraditórias não são necessariamente verdadeira, uma, e falsa, outra. Aristóteles divide as proposições em afirmativa (catáfase ou "o que declara algo acerca de outro") e negativa (apófase ou "declaração de que algo está separado de outro"). Estas formulações são importantes porque permitem precisar as categorias de Universal e Particular em termos que interessam aos desdobramentos da lógica proposicional.

Há quatro proposições derivadas da teoria aristotélica do Ser: (1) Universal afirmativa: todo S é P (A); (2) Universal negativa: nenhum S é P (E); (3) Particular afirmativa: algum S é P (I); (4) Particular negativa: algum $S$ não é $\mathrm{P}(\mathrm{O})$. Aqui, A e E não podem ser verdadeiras conjuntamente, embora possam ser ambas falsas. Por outro lado, I e O podem ser ambas verdadeiras, mas nunca ambas falsas. Segundo Aristóteles, não se pode predicar do sujeito, "de um modo geral”, como universal, aquilo que em sua natureza é único. Uma substância tem como característica, na lógica aristotélica, admitir qualidades contrárias "mediante uma alteração em si mesma". Assim, uma proposição referente a uma substância pode receber "os contrários" e permanecer a mesma. Aristóteles distingue então quatro modos de oposição: oposição de relativos ou 
correlativos (p. ex., dobro/metade); oposição de contrários (mal/bem); oposição privação-possessão (cegueira/visão); e da afirmação à negação (estar sentado/ não estar sentado).

Na lógica clássica, modalidade ou categoria modal é a característica, de proposições ou juízos, que determina o modo pelo qual se atribui um predicado a um sujeito (JAPIASSÚ; MARCONDES, 1990). Aristóteles introduz na filosofia as seguintes categorias modais: necessário, contingente, possível e impossível. Segundo a tradição aristotélica e medieval, as modalidades podem ser entendidas conforme o esquema: possibilidade: "É possível que S seja P"; impossibilidade: "É impossível que S seja P"; contingência: "É contingente que S seja P"; necessidade: "É necessário que S seja P". A proposição necessária é sempre verdadeira, em qualquer circunstância; a possível pode ser verdadeira ou falsa; a impossível é sempre falsa. À contingência Aristóteles não atribuirá valores, ou melhor, ele sustenta que há proposições para as quais se pode atribuir valor de verdadeiro e falso ao mesmo sujeito. Trata-se da categoria dos acidentes. Ao acolher o acidental - contingente - como uma das modalidades do ser, Aristóteles avança uma lógica quaternária que inclui proposições indecidíveis quanto aos valores verdadeiro e falso.

Antes de chegar a uma caracterização mais específica da contingência como estruturada pela lógica aristotélica, vale uma passagem pela etimologia (REY, 1993). O latim imperial registra o uso de contingens, particípio presente de contingere, que significa "tocar, atingir". Daí resvalou para "acontecer por acaso". O adjetivo surge com o sentido de "que acontece, mas não necessariamente", desenvolvendo-se em filosofia como o "não-essencial". Em matemática, a expressão "ângulo de contingência" recupera a noção primeira daquilo que atinge ou toca. O verbo "acontecer", assim como "acontecimento", provém do termo latino contigescere, que passa ao espanhol antigo contescer e chega ao português acontecer. Várias são as noções contidas no termo, dentre elas a de verdade (aconteceu); de algo que se tornou realidade; de espanto (o acontecido); de modificação que afeta algo ou alguém; de sucesso; de peripécia; de acidente.

$\mathrm{O}$ termo acidente opõe-se ao termo essência. No Organon, o tema da essência tem grande importância, aparecendo desde as primeiras linhas. Trata-se, porém, de uma concepção cuja nuança deve ser ressaltada. Aristóteles propõe uma formulação para certas proposições singulares. Trata-se da enunciação contingente: "a que, não sendo necessária, pode, todavia, ser 
verdadeira, ou a que pode ser, quer verdadeira, quer falsa" (ibid., p. 171). Nessa formulação, o contingente vincula-se ao possível quando "não sendo necessária, pode ser verdadeira." Já na segunda acepção - a que pode ser verdadeira e falsa - vemos caracterizar-se uma nova modalidade, um atributo que pode ser verdadeiro e falso sem que o sujeito da proposição caia. Uma característica que Aristóteles atribui ao contingente é a indeterminação com relação ao presente e ao futuro; dito de outro modo, o contingente caracterizase por ser indecidível quanto ao presente e ao futuro, mas não quanto ao passado. A modalidade contingência se emprega para eventos, acontecimentos - portanto, para ocorrências sobre as quais podemos apenas constatar ou analisar os efeitos.

Apesar de pretender discernir cada um dos quatro modais, Aristóteles não deixa de correlacioná-los. Ele afirma: "o que não pode ser é impossível que seja, e o que não pode ser, é necessariamente" (ARISTÓTELES, 1985, p. 136). Esta afirmação tem uma conseqüência imediata: é absurdo pensar que não há lugar para a contingência e que, pelo contrário, todas as coisas ocorrem por efeito da necessidade, porque, se assim fosse, haveria sempre a certeza de que "adotada uma dada conduta, o resultado estaria determinado, e que se não adotássemos essa conduta, o resultado não se atingiria" (ibid.). O resultado de uma ação é real, mas isto só pode ser constatado depois, ainda que se o preveja, como ironiza Aristóteles, "com dez mil anos de antecedência". Com o foco no real, Aristóteles afirma: "Mas que amanhã haja ou não haja uma batalha naval, eis o que é necessário". Deste modo, ele aproxima o necessário do possível, tomando o conhecimento como estreitamente ligado à categoria de "causa". Assim, uma apreensão lógica dedutiva do mundo seria condição exclusiva para o conhecimento no regime da necessidade. Como vimos, em Aristóteles, três são os princípios que sustentam a lógica dedutiva: o princípio de identidade, o princípio da não-contradição, e o princípio do terceiro excluído. Ocorre que, ao trazer a categoria da contingência, ou do acidental, ele praticamente desmonta tais princípios. Eis sua definição mais desconcertante para acidente: "aquilo que está presente e ausente sem corrupção do sujeito"1 (p. 111). De acordo com esta lógica, ao afirmar uma particular e sua oposta - por exemplo, "algum animal é justo" e "algum animal não é justo" - é possível dizer que elas podem ser simultaneamente verdadeiras ou simultaneamente falsas.

Aristóteles busca entender como se comportam as afirmações e negações referidas aos modais. $\mathrm{O}$ curioso é que, ali, ele se refere às seguintes categorias: o possível e o não-possível, o contingente e o não-contingente, o impossível e o necessário. Não temos mais dois pares de opostos, mas três, 
onde é evidente a relação de contrários entre impossível e necessário, cabendo às demais tão somente suas próprias negações. É deste modo que a enunciação "é possível" tem como negação duas possibilidades: ou "é possível que não" ou "não é possível". Nesta lógica, fica claro que o que é em potência nem sempre será em ato, "de sorte que a negação também lhe pertence, porque o que é capaz de passear é também capaz de não passear" (ibid., p. 153). É difícil separar o contingente do possível; Aristóteles considera-os termos adjuntos. Se as proposições não são contraditórias entre si, pode-se dizer de uma coisa que ela é $e$ não é. Assim, "é possível que seja" não contradiz "é possível que não seja”. E, por outro lado, "da proposição “é possível ser' segue-se 'é contingente ser’, proposição que é recíproca com a primeira” (ibid., p. 156). Daí, podemos concluir que estas proposições são eqüipolentes e "se é possível, é contingente" (ibid., p. 173), diz ele.

Sobre a relação de oposição entre impossível e necessário, Aristóteles leva-nos a pensar que estes opostos se tocam, pois, segundo seu argumento, predicar a impossibilidade implica - ou é o mesmo que - afirmar a necessidade. Este raciocínio não pode ser estendido na relação do possível com o necessário, "Porque, quando é necessário que uma coisa seja, é também possível que ela seja, caso contrário teríamos a negação implícita" (ibid., p. 158). Ora, dizer "é possível" tem como correspondente "não é impossível"; se "não é impossível", segue-se que "não é necessário". Prossegue Aristóteles: "Uma coisa pode ser e todavia não ser, mas se é necessário que seja, ela não pode simultaneamente ser e não ser" (ibid., p. 159). Ser e todavia não ser é a definição da contingência, do que acontece por acidente: aquilo que está presente e ausente sem corrupção do sujeito.

Aristóteles propõe uma questão que interessa ao tema deste ensaio: uma afirmação teria seu contrário na negação ou em outra afirmação? Para responder à questão, é bom saber que ele está investigando os juízos. A partir da forma lógica básica "S é P" (juízo assertótico), podem-se reunir duas ou mais idéias numa unidade, o uno ao qual Aristóteles se refere, quase sempre o qualificando de acidental ou não-essencial. Assim, se temos "homem" e "justo", acidentalmente podemos dizer "o homem é justo", bem como sua negação. De todo modo, a lógica proposicional obedece às leis da linguagem. Dizer "o homem é justo" significa atribuir-lhe uma qualidade afirmativa; do mesmo modo, dizer "o homem é injusto" também é atribuir-lhe uma qualidade afirmativa. 
Destacar a modalidade contingência dentre as categorias lógicas determina uma visão de mundo não-dualista, que nos parece ser a de Aristóteles em contraposição àquela de seu mestre, Platão. Trata-se de uma lógica onde estão em jogo análises combinatórias e não apenas classificações. Mais do que isso, impõe-se a questão do desejo, pois, de fato, é a subjetividade dos sujeitos que se encontra interrogada a cada ação política que, por sua vez, determinará uma chamada às consequiências, ainda que indeterminadas a priori. Ora, se o que está em jogo são combinações, mudanças na estrutura da cidade, pode-se observar, nos escritos de Aristóteles, uma clara distinção entre posições e papéis: homem ou indivíduo não são categorias a serem sobrepostas à de sujeito, visto que se os indivíduos permanecem num regime político que não muda, a posição de cada cidadão, por outro lado, se modifica. Sem esta compreensão, a vida social seria tomada na esfera natural, onde as mudanças e os ciclos se sucedem e se reproduzem com regularidade. Dizer que a vida humana foge ao regime do natural é dizer não à prerrogativa do necessário como primazia do humano, pois ainda que se possa advogar a existência do contingente na natureza, isto de nada vale se não houver um reconhecimento significante para retroativamente produzi-la "de fato", ou seja, integrá-la na cadeia simbólica de trocas².

Usando curiosamente como ilustração um tema do nosso maior interesse - conceitos de saúde-doença - conclui Aristóteles (1985, p. 99) que há casos em que não é necessário que um dos opostos seja verdadeiro e o outro falso: "por exemplo, saúde e doença são contrários, mas nem um nem outro é verdadeiro nem falso". Dizer "o homem é sadio" significa atribuir-lhe uma qualidade afirmativa; do mesmo modo, dizer "o homem é doente" também é atribuir-lhe uma qualidade afirmativa. Mas será que é o mesmo afirmar "é doente" e "não é sadio"? É o que Aristóteles quer saber, quando pergunta: "qual o juízo verdadeiro contrário ao juízo falso: é o juízo da negação, ou esse que enuncia afirmativamente o contrário? Será que há um único juízo contrário ou pode haver pluralidade de contrários?" (ibid., p. 163). Para Aristóteles, somente são contrários os juízos em que há erro. Aqui, erro é definido comparativamente: "como uma transição". Errar é transitar de um extremo a outro, diz Aristóteles. "Sendo assim, o bom é ao mesmo tempo bom e não mau; a primeira destas qualidades pertence-lhe por essência, e a segunda, por acidente, pois só por acidente o bom é mau" (ibid., p. 164).

A partir de Aristóteles, a filosofia vai sendo construída, alimentando-se e destacando-se, pouco a pouco, do pensamento religioso. Michel Foucault destaca, em Les mots et les choses (1966), que a partir do estoicismo, o sistema 
de signos torna-se ternário, estando em jogo o significante, o significado e a conjuntura. Assinala que no Renascimento, ainda que haja a mesma estrutura, sua organização é mais complexa, pois estes três elementos, diz ele, se resolvem em uma figura única. O século XVII vai operar, segundo Foucault, uma redução e "a disposição dos signos se tornará binária, pois será definida, com PortRoyal, pela ligação de um significante e um significado" (FOUCAULT, 1966, p. 57). Não esqueçamos que se encontra aí o marco de constituição do pensamento racionalista que promoveu a epistemologia cartesiana baseada na dualidade mente-corpo. Não obstante, contra o pensamento dualista e determinista, ainda nesse século constituiu-se outra vertente filosófica que não chega a vingar como projeto hegemônico, mas que pode ser útil para pensarmos a constituição do campo epidemiológico hoje. Trata-se da contribuição de Blaise Pascal (1623-1662).

Pascal foi contemporâneo de René Descartes, com quem polemizava. Ambos pretendiam aliar a Verdade científica à Verdade cristã. Porém, enquanto Descartes respondia aos anseios organizadores do mundo moderno racional, Pascal apostava num mundo cuja natureza comportasse vazio e acaso (CHAUÍ, 1999). De acordo com Chevalley, sua escritura pontual, seu estilo dialogal e irônico, juntamente com alguns elementos epistêmicos notáveis, promovem uma “epistemologia anticartesiana" (CHEVALLEY, 1995, p. 8).

A visão pascalina do mundo e das ações humanas é não-totalizante: "Não tireis de vosso aprendizado a conclusão de que sabeis tudo, mas sim a de que vos resta infinitamente a saber" (PASCAL, 1999, p. 91). Vale a pena ressaltar alguns pontos da filosofia de Pascal que podem contribuir para pensar metodologicamente nosso tema neste ensaio:

1. a questão do correlato do objeto no mundo ou na representação não é relevante;

2. a racionalidade pode ser pensada como um saber não-universal e não-necessário;

3. as verdades são circunscritas às regiões nas quais a experiência foi produzida;

4. os objetos não se apresentam naturalmente: são relacionais, construídos. 
Chevalley (1995) aponta as seguintes linhas de pensamento anticartesiano em Pascal: o objeto matemático ou físico não é uma idealização do objeto natural do qual se revelaria uma essência, mas é pensado em termos de relação (rapport); a Natureza não obedece a leis universais e necessárias, sendo um processo sujeito a variações e submetido a flutuações; o conhecimento é um saber que não é seguro nem neutro, tampouco independente de seu objeto, mas constitui-se como incompleto e submetido às próprias condições de enunciação. Assim, o conhecimento adquirido é singular, como devem ser os métodos, não havendo, portanto, instrumentos neutros nem objetos descolados dos sujeitos que o produzem. Foi pensando desta maneira que Pascal inventou o cálculo do acaso, raiz da teoria das probabilidades, substrato do conceito epidemiológico de risco.

Lacan revela-se intrigado com o fato de que tenhamos atravessado séculos sem saber que uma lógica pode prescindir do princípio da contradição. A esta pontuação de Lacan, acrescentamos que nem mesmo Foucault, magistral historiador das idéias, anotou a presença da lógica modal aristotélica anterior aos estóicos. Trata-se, como vimos, de uma lógica quaternária, tanto em sua apresentação relativa aos eventos (necessário, possível, impossível e contingente) quanto na sua apresentação causal (material, final, eficiente e formal). Ao retomar a estrutura quaternária modal e examinar proposições que hoje designamos como indecidíveis, Lacan reconhece e destaca as aberturas promovidas por Aristóteles e Pascal. Seu grande interesse na lógica aristotélica encontra-se na utilização de proposições gramaticais esvaziadas de sentido, tornando-as ditos que se manipulam (LACAN, Sem. XXI, aula de 12/02/1974, inédito). Desta maneira, Lacan retomará os quatro modais, mais de dois mil anos depois, para extrair deles todo o seu rigor lógico. Em várias oportunidades, Lacan define a Lógica como a ciência do Real. Para ele, a lógica introduzida por Aristóteles faz da verdade "um valor vazio [...] uma maneira de tratar a verdade que não tem nenhum tipo de relação com o que chamamos comumente de verdade" (ibid., aula de 9/04/1974, inédito).

A recuperação da lógica aristotélica operada por Lacan deriva de dois princípios que ele julga importante assinalar: não há universo de discurso nem tampouco um significante que possa dar conta do Outro. Essa formalização não incide somente sobre a psicanálise, mas atinge diretamente a epistemologia das ciências. Milner (1996) analisa o argumento de Popper, de que as proposições científicas devem ser refutáveis. Só que a refutabilidade de uma proposição depende de um ponto: "se sua negação não for logicamente contraditória ou 
materialmente invalidada por uma observação [...] seu referente deve poder lógica ou materialmente - ser outro que é. Mas isso é a contingência" (ibid., p. 50). Conclui, então, que somente uma proposição contingente é refutável: "só existe, portanto, ciência do contingente".

Badiou (1993) também ressalta a importância do conceito de contingência, afirmando que há casos em que é vão interrogar sobre a veracidade do fato/feito. Quando a contingência ou o impossível estão em jogo, o resultado é indecidível, por vários motivos. Em primeiro lugar, a verdade tem estrutura de ficção e se constitui por uma abolição da cena, isto é, na sua ausência. Outra maneira de dizer que o símbolo mata a coisa. Não há a verdade toda, assim como não há transcendência com relação à verdade, pois ela depende da situação em que ocorre. A verdade, sob a forma de um dizer, resiste ao princípio da nãocontradição, pelo simples fato de operar com a linguagem, sistema no qual o signo nunca corresponde biunivocamente ao seu referente.

Atualmente, a lógica aristotélica, também conhecida como lógica clássica, é tida como superada pela lógica paraconsistente, desenvolvida por Newton da Costa (1980), ou pela lógica do "não-todo", nomeada por Lacan. Esses desdobramentos encontram seus fundamentos nos famosos Teoremas de Gödel, formulados entre 1930 e 1931, em três artigos: "Alguns resultados matemáticos sobre completude e consistência"; "Sobre as proposições indecidíveis dos Principia mathematica e sistemas correlatos I" e "Sobre a completude e consistência". É possível sustentar que os Teoremas de Gödel provêm do sistema lógico aristotélico. O primeiro teorema ("Em qualquer teoria axiomatizável, coerente e capaz de formalizar a aritmética, pode-se construir um enunciado matemático que não pode ser provado nem refutado nesta teoria") afirma que uma teoria proveniente da matemática é necessariamente incompleta, pois existem enunciados que não são demonstráveis e cuja negação tampouco é demonstrável. Tais enunciados são chamados indecidíveis. O segundo teorema [Se T é uma teoria coerente que satisfaz hipóteses análogas, a coerência de $\mathbf{T}$, que pode ser expressa na teoria $\mathbf{T}$, não é demonstrável em $\mathbf{T}$ ] diz que a coerência da teoria não pode ser demonstrada internamente; é necessário um discurso exterior para validar um campo do conhecimento.

Com esses teoremas, pode-se dizer que, no âmbito de ciências fundamentais como as matemáticas (e em suas aplicações, como a Epidemiologia) Gödel liga, de maneira inesperada e não trivial, a consistência à incompletude. Apesar disso, Gödel postula que consistência não é sinônimo de 
completude, pois há proposições matemáticas sobre as quais não se pode deduzir se são verdadeiras ou falsas. Rejeita assim o princípio do terceiro excluído, imposto pela Lógica Bivalente (LIMA, 1993; HEIJENOORT, 1967).

\section{Fundamentos lógicos dos conceitos de causa e risco}

O conceito epidemiológico de risco sustenta-se como aplicação da lógica indutiva e da lógica dedutiva, respectivamente, a problemas particulares e a problemas gerais de determinação de fenômenos de saúde-doença. A lógica indutiva, formalizada por Platão, parte do particular para o universal, a partir de repetições - ou tentativas de reprodução - de eventos em sua regularidade. Os ensinamentos platônicos perseguem, pela observação de certos fatos, a adoção ou rejeição de padrões de conduta a serem por "todos" seguidos. Embora a indução, em sua leitura contemporânea, seja ancorada na teoria probabilística, há uma gama de problemas não solucionados, como a generalização dos resultados e sua pretensão à totalização (JAPIASSU; MARCONDES, 1990).

Pela vertente de uma história da lógica, seria interessante examinar dois momentos fundantes do determinismo epidemiológico. O primeiro, localizado em algum momento precoce da emergência da modernidade, marca a constituição de um discurso "iluminado" sobre os conceitos de Estado e de população (e sua saúde, ou suas doenças). Além disso, buscava-se o desenvolvimento de tecnologias para contagem de indivíduos (como se fazia com as estrelas) enquanto cidadãos de um Estado - e daí a disciplina chamada Estat-1́stica. A principal consequiência de tais movimentos no campo de operação da interpretação científica terá sido a invenção pascalina do acaso enquanto categoria epistemológica, viabilizada pelo conceito de probabilidade (ELSTER, 1984; HACKING, 1990). O segundo momento pode ser identificado entre os anos 1920 e 1950, no processo de evolução da ciência e técnica epidemiológicas, tal como descrito por Susser (1987) e Ayres (1997), que resultou na construção da noção de risco como conceito fundamental da ciência epidemiológica.

Neste momento, é preciso questionar a própria natureza dos nexos construídos pelo conhecimento epidemiológico, comumente designados pelo rótulo genérico de causa. A insistência dos poucos teóricos da ciência epidemiológica em debater a questão da causalidade reafirma a intenção de uma tradução literal de associações pseudoprobabilísticas de risco como se fossem legitimamente relações de produção de efeitos, ou simplesmente causas. 
Esta tentativa de apresentar correlações entre variáveis como nexos causais entre fenômenos concretos, que termina por tomar a causa como um processo natural (e, por conseguinte, anistórico), é aparentemente simplória e fácil de refutar. Porém, rapidamente constatamos que não é bem assim, já que tal abordagem representa a aplicação de uma teoria de causalidade baseada no senso comum típico da cultura ocidental na modernidade tardia (BECK, 1996).

Para abordar esse problema, analisemos o fundamento lógicoepistemológico deste modo de raciocinar, destacando quais são as operações metafóricas primevas que o viabilizam. O termo "pressuposto metafórico" referese a figuras (ou elementos imaginários) que em princípio se tem necessariamente que imaginar a fim de operar (e enxergar, compreender, seguir, interpretar etc.) no interior do referencial de pensamento. Os pressupostos metafóricos da lógica causal são basicamente três: as metáforas de evento, nexo e fluxo.

Em primeiro lugar, a metáfora de evento carrega o sentido de algo discreto, no sentido de isolado, distinto, destacado, fragmento de uma realidade ampla e complexa (CASTORIADIS, 1992). O mundo (real ou virtual) é metaforicamente traduzido como universo de entidades individuais que podem ser potencialmente incluídas ou excluídas de agregados chamados "conjuntos". Um evento, para merecer esta designação, deve ser identificado enquanto tal quer dizer, como diferente do resto das coisas, de todas as outras coisas, do que ele não é, do que o antecede, do que ele determina (ZOURABICHVILI, 1994). Em uma palavra, deve ser visto como "outra coisa". Neste sentido, entretanto, os limites também são fabricados, e para se tornar objeto de conhecimento, a coisa-fato-processo-fenômeno terá obrigatoriamente que ser isolada de um todo (ainda) indiferenciado.

A operação mais fundamental (embora aparentemente óbvia) e de fato indispensável para se pensar a causalidade consiste na distinção entre causa e efeito. Articulando diretamente as teorias aristotélicas do Ser, do Evento e da Causa, é preciso que a causa, o evento $\mathbf{C}$ (chamemos de antecedente, determinante) seja distinto do restante das coisas, diferente do indiferenciado: $\mathbf{C}$ tem de ser diferente de $\neg \mathbf{C}$ (não $\mathbf{C}$ ). Da mesma forma, algum outro evento significativo chamado D (de doença, outcome, efeito), deve também ser diferente do resto, do todo indiferenciado do qual ele faz parte, do $\neg \mathbf{D}$ (não $\mathbf{D}$ ). Ora, $\mathbf{C}$ como parte de $\neg \mathbf{D}$ e $\mathbf{D}$ como parte de $\neg \mathbf{C}$ são diferentes entre si. Portanto, têm sua própria identidade definida em relação à identidade do outro, sendo ambos distintos e não redutíveis a $[\neg \mathbf{D}, \neg \mathbf{C}]$, por suas próprias definições 
e propriedades enquanto eventos isolados. Em síntese, num modelo causal, C será sempre diferente de $\mathbf{D}$, e nunca deverá ser confundido ou reduzido a $\mathbf{D}$. Conclusão: a distinção entre causa e efeito é construída através desta operação elementar, sem o que tais termos jamais encontrariam sua identidade e seu lugar preciso na esfera da referenciação causal.

Vejamos a segunda metáfora, a noção de nexo. Neste sentido, nexo implica a reunião deste antecedente causa com aquele conseqüente efeito (que chamamos aqui $\mathbf{D}$, doença). Matematicamente, a ocorrência de um dado evento $\mathrm{D}$ em função da sua causa $\mathrm{C}$ é definida a partir da seguinte forma geral: $\mathrm{D}=\mathrm{f}$ (C). No jargão da chamada Epidemiologia moderna, trata-se da "função de ocorrência do risco" (MIETTINEN, 1985). O nexo C-D é um laço, ligação, relação, conexão, vínculo entre eventos que, anteriormente separados, precisam reunir-se naquela totalidade que se constrói como conhecimento científico. Para definir essa reunião como uma causa, deve-se necessariamente enunciá-la de dentro de um referencial extra-científico particular, o causalismo.

Não obstante a consagração do uso, causalismo não é o mesmo que causalidade. Causalismo é uma doutrina, um modo de pensar a causa (BUNGE, 1969). Neste caso, causa aparece como uma força, uma Grande Razão organizadora do mundo, externa aos objetos, para além e em torno dos eventos, movendo-os. Sobretudo, o nexo causal é pensado como uma conexão linear, não-complexa, unívoca e, enquanto tal, dimensionável. Esta propriedade de dimensionalidade justificaria o uso de operações de quantificação para descrever a natureza do nexo causal. Trata-se de uma propriedade genética dos objetos, assim como a sua entidade, ou a sua essencialidade, tanto como sua forma; um atributo destacável do objeto, e como tal descritível, vulnerável a processos de inquirição sistemática. Neste contexto, a investigação científica implica o estabelecimento de funções de determinação como descritores da natureza hipoteticamente causal dos nexos enfocados.

A validação da função determinante enquanto função causal não é dada imediatamente pela precisão dos procedimentos de medida empregados para estabelecer tal função, nem pelo contraste frente aos modelos estatísticos de distribuição teórica de eventos usados para descartar explicações estocásticas de seleção amostral para padrões de dados peculiares. De fato, a validade das proposições de causalidade se constrói por meio de um processo heurístico complexo, de algum modo simplificado pela aplicação de critérios de causalidade a associações tipo exposição-doença (WEED, 1986). Nesta "hermenêutica 
epidemiológica", os critérios relacionados à inferência são de capital importância como instância particular do problema fundamental das relações parte-todo característico do método da indução.

Samaja (1994) comenta que as relações entre elementos constituem, portanto, relações de partes extrapartes, ou melhor, relações de exclusão de partes alienadas de uma totalidade, frente à distinção entre causa e doença. Que os elementos sejam homogêneos ou diferentes entre si e que eles sejam componentes de um mesmo conjunto ou sistema de conjuntos é inteiramente dependente de um processo decisório do pesquisador (enquanto membro de uma instituição sócio-histórica chamada ciência, ou no caso, Epidemiologia), e não resulta determinada primariamente pelos movimentos concretos dos elementos no sistema. Em qualquer aproximação teórica com um grau mínimo de esclarecimento, o todo enfim consegue ser reconhecido como mais do que a soma das partes, porém sua determinação poderá ser ainda identificada com a soma das determinações individuais (de natureza causal) de cada uma das partes isoladas. A lógica clássica concebe as relações entre partes e todo como de natureza meramente topológica (i.e. conteúdo-continente), porém a relação entre as partes é de mútua exclusão (externalidade) e, quando se aplica, de determinação causal. O subconjunto de causas, ou variáveis independentes (para usar uma terminologia corrente entre os metodólogos), deve ser claramente diferenciado do subconjunto de efeitos, as variáveis dependentes, também no sentido de evitar transgredir as regras lógicas de conexão. A lógica clássica considera que a determinação circular (ou de causalidade recíproca) constitui um paradoxo intolerável e, portanto, um efeito não pode em nenhuma hipótese ser a causa da sua própria causa (SAMAJA, 1994).

Não obstante, se conceituarmos os fenômenos da saúde-doença-cuidado enquanto processos sociais [pois o bio do biológico está submetido ao social que o nomeia e descreve, portanto bio+lógico], e se também aceitarmos o pressuposto de que os processos sociais são corporais, históricos, complexos, fragmentados, conflitivos, dependentes e incertos (em uma palavra: contingentes), então os modelos causais, significando estruturas de determinação efeitoespecíficas, não serão os dispositivos heurísticos mais adequados para a referenciação de tais objetos. É verdade que o discurso médico contemporâneo aceita de bom grado a idéia de complicação entre os nexos de causa e efeito, assumindo que uma causa pode produzir muitas patologias e que uma mesma doença pode ter diversas causas. No entanto, no horizonte (ou no nível do imaginário científico corrente), o modelo explicativo correspondente alimenta- 
se ainda do sonho do efeito específico condicional a um dado subconjunto de causas (VINEIS, 1997), a ser "descoberto" pelo avanço da pesquisa científica.

Em outras palavras, não mais se postula a unidade e especificidade da causa, mas ainda a unidade e a especificidade de uma dada configuração de causas poderão dar conta do entendimento positivo da ocorrência dos fenômenos da saúde-doença. Em um sentido preciso, o termo "multicausalidade" nada informa em relação à natureza potencialmente complexa das conexões, ou funções de risco, em pauta. Tal proposta de multicausalidade, no sentido estrito de múltiplas causas para um dado efeito, não é capaz de superar o problema fundamental desta lógica: os nexos do processo de determinação das doenças são ainda de natureza causal, enquanto fatores, sempre esperados como efeitoespecífico. No caso em pauta, a noção de efeito-especificidade é simplesmente transferida a um nível hierárquico mais elevado, do nexo de causa única à especificidade de um complexo de causas, como, por exemplo, nas "tortas" de causalidade de Rothman e Greenland (1998). Nesse sentido, ser uni ou multicausal é irrelevante para a classificação de qualquer modelo determinista, dado que o critério classificatório efetivo é a natureza do nexo que sintetiza a relação de determinação. Como tal, a expressão "multicausalidade" não indica qualquer aumento substancial do nível de complexidade. Multiplicar causas e/ ou efeitos em algum modelo explanatório não resolve as limitações fundamentais do causalismo, e nada nos diz em relação à natureza potencialmente rica e diversa das funções de risco (VINEIS, 1997). Tal abordagem, ainda no sentido preciso, porém restritivo dos manuais epidemiológicos, refere-se exclusivamente à complicação, e não à complexidade.

Falta ainda um elemento para completar a série metafórica constitutiva do objeto epidemiológico: trata-se da noção de fluxo, aqui no sentido de assimetria, temporalidade, direcionalidade. Tomemos essa metáfora como basicamente uma expressão da representação espacial ou linear do tempo, característica fundamental do modo moderno de pensar, apesar de parte essencial da lógica subjacente mais arcaica e primitiva da nossa cultura (FABIAN, 1983). Uma determinada relação de ordem referida a uma seqüência dada de eventos, tomada como uma abstração espacial, tem sido designada como temporalidade, integrando-se na lógica conjuntista fundante do pensamento ocidental (CASTORIADIS, 1982).

O pensamento convencional sobre a temporalidade se estrutura por referência a termos de lugar ou espaço, o que "permite uma identidade ao 
diferente" (CASTORIADIS, 1982). A diferença se verifica no decorrer de um tempo que se retém de momento a momento como uma "preservação ideal do passado" - ou seja, como um lugar ontologicamente determinado. Definido como ordem de sucessão, o tempo é sempre referencial e assim permite ao "idêntico diferenciar-se de si mesmo", pela retenção desse espaçamento temporal virtual e metafórico (e, portanto, lingüístico). Nessa perspectiva, ser "outro" não significa a mesma coisa que ser "diferente de", e a emergência do outro resulta de uma gênese ontológica, quer dizer, da criação de algo "totalmente novo". Assim é que o tempo "é a verdadeira manifestação do fato de que surge um "outro" em relação ao que já existe, trazido à existência como novo ou como outro e não simplesmente como conseqüência ou como um exemplar diferente do mesmo" (ibid., p. 185).

A teoria aristotélica do Ser, usada como fundamento do determinismo inerente à lógica conjuntista-identitária, tem sido tomada como incapaz de incorporar a "emergência", ou ontogênese radical, na medida em que, ao atribuir causalidade a cadeias de categorias preexistentes, apenas descobre variação ou diferença no mesmo ser (mas não o "outro novo"). Dessa maneira, poderse-ia responsabilizar a apropriação mais comum desta lógica pela paralisia dos modelos explicativos da realidade, posto que estes operam através do congelamento das categorias básicas do Ser. Ademais, neste modo de pensar, a sucessão de eventos históricos é considerada como indício da causalidade, pelo menos em relação às propriedades particulares dos objetos. De fato, o primeiro e mais fundamental dos famosos critérios epidemiológicos de causalidade de Hill, "sequiência temporal", constitui um exemplo claro de aplicação deste tratamento convencional da temporalidade em um campo científico particular. Nesta perspectiva, as categorias são imunes à transformação radical, ou criação de alteridade, além de abertas à certeza, por definição assumidas como universalmente válidas além dos requisitos mínimos da referência cultural e social.

Causalidade meramente indica uma propriedade genética do evento ou fenômeno, de certa maneira equivalente à temporalidade (ou existência na ordem maior das sucessões). Porém a temporalidade sócio-histórica implícita de uma dada sociedade (bem como sua relação com a temporalidade "natural") simultaneamente determina e se sujeita às metáforas que constituem as dimensões significativas do seu "imaginário social" (CASTORIADIS, 1982). Dentro do referencial conjuntista-identitário herdado de uma das vertentes do pensamento aristotélico, a causalidade somente pode ser compreendida como fluxo, a partir de uma série de eventos do passado, resultante de uma 
temporalidade. Porém o tempo é socialmente instituído, dado que cada sociedade o representa através de uma temporalidade explícita (tempo marcado e significante) e uma temporalidade implícita (alteridade-alteração), que se referem mutuamente e, em última medida, buscam se sobrepor a certo senso de "tempo natural" (FABIAN, 1983).

Aceitar a causalidade ou determinação do objeto de conhecimento como sua propriedade essencial implica necessariamente a adoção da tese metafísica da essência-substância, junto com o referencial identitário da "instituição socialhistórica do evento", parafraseando uma expressão de Castoriadis (1982, p. 200). A ontologia básica do Ocidente, a noção do que é um evento, a cada instante é canalizada através desse marco conjuntista-identitário, que atribui a certas determinações de figuras ou imagens uma identidade geral que a constitui como objeto. Como resultado, este simples e inadvertido ato termina por reificar as propriedades da determinação, tomando a causalidade, enfim, uma entidade autônoma, "cimento do universo" (RORTY, 1989). Ao perceber determinações e figuras parciais e limitadas como coisas integralmente determinadas e substantivas, como objetos, o pensamento ocidental obscurece o fato de que a gênese ontológica alteridade-alteração pode não cessar de ocorrer - isto é: ser necessária - em todos os momentos, como contingências ou acidentes.

A questão do raciocínio preditivo em Epidemiologia revela-se, portanto, dependente de uma definição linear do tempo, na perspectiva de uma temporalidade "espacializada", o que exclui deste raciocínio a possibilidade de considerar a emergência radical (alteridade) e, portanto, a contingência, na medida em que estas necessariamente implicam imprevisibilidade. Além disso, descobrimos que a noção de predição, mesmo em um contexto de aplicação técnica como na prática epidemiológica, usualmente não é empregada no sentido mais restrito de uma verdadeira predição. Baseando-se no conhecimento sobre casos particulares de uma dada amostra, é possível predizer, para o futuro, a ocorrência no tempo de novos casos em uma dada amostra, como parte de uma variação que, aceitando a metáfora do tempo espacializado, poderíamos chamar de "predição longitudinal". Por outro lado, pode-se "predizer" apenas metaforicamente (o que, aliás, ocorre com muita frequiência), não como uma antecipação para um tempo futuro que ainda não terá ocorrido, mas como uma afirmativa sobre o desconhecido, sobre o ainda-não-estudado, numa variação que podemos denominar de "predição seccional". Neste caso, rigorosamente, o que chamamos de predição não é de fato uma "predição" mas sim uma "pseudopredição". 
Ora, uma predição verdadeira pode ser validada somente por referência a uma perspectiva filosófica particular, o assim chamado indutivismo. Para Popper (1968), não há garantia lógica ou filosófica de que uma dada observação terá poder antecipatório para certo futuro, ainda não existente concretamente. Todavia, para tentar organizar as ações do presente, de acordo com a teoria das probabilidades; é possível, desde Pascal, pensar o futuro em termos probabilísticos, a partir de estratégias tipo apostas, lances ou jogadas. Por outro lado, a "pseudopredição", mesmo não sendo de fato uma predição porque não constitui nenhuma antecipação no tempo, como sabemos, poderá, no entanto, ser válida e legítima, no sentido de que, pelo menos num certo âmbito, sob pressupostos explícitos e dentro de uma perspectiva operativa (como por exemplo, no raciocínio da estatística inferencial), haverá uma lógica subjacente constituindo um conjunto de leis formais que a fundamentam. Podemos esclarecer esses argumentos com o auxílio da figura 1. É aceitável que alguns achados da amostra $\mathbf{A}$ podem ser tomados como base de predição para um estado futuro desta mesma amostra, tal como representado por $\boldsymbol{f A}$ (futura amostra). Sob o pressuposto de condições inalteradas ou ausência de variação temporal no comportamento da amostra, $\mathrm{A}$ 〉> $\boldsymbol{f} \mathbf{A}$ é uma predição longitudinal válida, legítima e verdadeira. Por outro lado, proposições derivadas da amostra $\mathbf{A}$ e expandidas à sua população de referência $\mathbf{P R}$ (ou $\mathbf{A} \gg$ > $\mathbf{P R}$ ), tal como no processo padrão de inferência empregado pelo chamado raciocínio epidemiológico, podem ser validadas sob pressupostos bastante rígidos, legitimadas pelas técnicas da estatística aplicada que, por sua vez, busca sua própria validade nos princípios da lógica matemática (OAKES, 1990). Portanto, A \> PR, apesar de válida e legítima, ainda é uma pseudopredição.

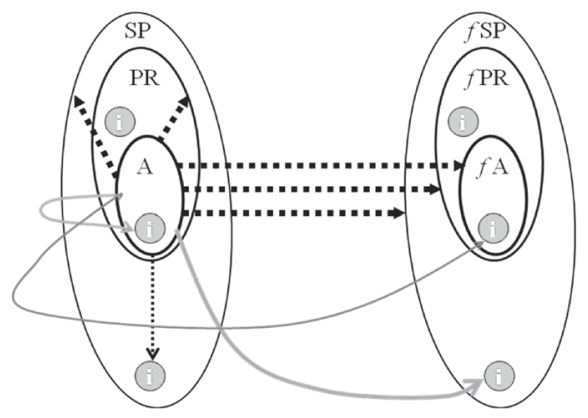

Figura 1 - Formas, trajetórias e limites da inferência e da predição 
Pseudopredições de nível mais elevado como A $\gg$ > SP (da amostra A para a população geral, ou superpopulação $\mathbf{S P}$ ) podem ser validadas pela lógica indutiva, na medida em que se baseiam numa expectativa de regularidade reforçada pela replicabilidade da investigação. Isto equivale ao item consistência dos critérios de causalidade de Hill, que dessa maneira se torna igualmente vulnerável à crítica geral dirigida ao raciocínio indutivo. Entretanto, $\mathbf{A}$ >> $\mathbf{S P}$ não é uma proposição legítima em relação à aplicação do raciocínio instrumental da estatística, porque extrapola o nível restrito da população de referência PR. A extrapolação combinada de uma amostra para uma população de referência no futuro (A > > fPR) constitui uma pseudopredição não-válida, não-legítima, evidenciando a insustentabilidade dos pressupostos necessários para sua aceitação - o que certamente inclui o cross-level bias referido por Susser (1994). Paradoxalmente, o tipo de predição mais "fraco" (da amostra A para uma futura superpopulação $\boldsymbol{f S P}$ ) tem sido exatamente o mais empregado nas propostas de aplicação de achados epidemiológicos para o planejamento de saúde. Não existe suporte - lógico, epistemológico, estatístico - para tal movimento preditivo "hiper-estendido".

Ainda na figura 1, podemos observar uma clara ilustração de algumas das limitações de um tipo especial de extensão de conhecimento: a predição individual, que implica uma "intrapolação" para o nível individual de resultados gerados na investigação de população. De acordo com as premissas estabelecidas acima, trata-se de outro caso de pseudopredição. Com base no que se conhece de uma amostra $\mathbf{A}$, a lógica dedutiva pode validar uma dada conclusão sobre o sujeito individual (I), formando uma proposição inferencial A 〉> (I), sob o pressuposto da homogeneidade interna do conjunto amostral. Ora, proposições do tipo A >> (I) constituem casos de pseudopredição, válidos somente se todos os (I)s forem iguais. De um modo menos rigoroso, o investigador pode assumir que os atributos dos (I)s seriam equivalentes a uma variável sintetizadora ou a um valor médio, em todos os casos homogeneamente distribuídos na amostra.

Para Samaja (1994), ainda que com freqüência se considere a relação causal como a única "determinação" com força explicativa, o certo é que: i) ela não é a forma exclusiva (nem sequer uma modalidade privilegiada) da determinação explicativa; e ii) não há uma única interpretação possível de seu conteúdo. A causalidade consiste em uma das muitas categorias que o cientista pode empregar para determinar seu objeto de conhecimento, ou seja, estabelecer 
as proposições que descrevem suas características e expõem os nexos que regulam suas transformações.

Nessa perspectiva, em vez de etapa metodológica necessária para o processo interpretativo da ciência, a inferência causal, em qualquer das suas modalidades, revela-se como uma pretensão. Trata-se de um pretensioso esforço de romper as barreiras do tempo e do espaço, procurando trazer uma ilusória perenidade ao conhecimento (provisório, como todos sabemos) restringido por estas barreiras. Tempo e espaço são definidores da singularidade (o que inclui a identidade conjuntista castoriadiana), mas o que formatos de investigação como o da Epidemiologia buscam é justamente a generalidade. Por tudo isso, podemos mesmo dizer que a relação tempo-espaço constitui uma das contradições fundamentais da ciência em geral, no que a "epidemiologia da pessoa, tempo e lugar" (MACMAHON; PUGH, 1970) seria apenas uma patética tentativa de escamotear tal contradição. De fato, todo o processo de produção de conhecimento como referência global e universal não passa de um esforço permanente para superar tal paradoxo, certamente com importantes subprodutos manifestados pelo avanço da tecnologia.

\section{Revisitando o conceito epidemiológico de risco}

O conceito de risco aparece nos textos básicos do campo epidemiológico como um construto operacional, com uma definição técnica. Nesse discurso, o conceito de risco privilegia o componente menos importante da reserva semântica agregada ao risco no discurso social comum, que é a dimensão da probabilidade. O sentido secundário de possibilidade de ocorrência de eventos se traduz como a probabilidade de ocorrência de eventos ou fenômenos ligados à saúde, integrado como dimensão fundamental do conceito nesse campo. Apenas subsidiariamente, na sua origem, o conceito de risco na Epidemiologia envolvia a idéia de dano, tanto que cada vez mais se fala em risco também se referindo a prognósticos positivos.

Risco em Epidemiologia equivale a efeito, probabilidade de ocorrência de patologia em uma dada população, expresso pelo indicador paradigmático de incidência. Esta formulação se deve a Olin Miettinen, autor de um trabalho controverso, audacioso (no seu tempo), denominado Epidemiologia teórica. Aí se encontra a primeira referência explícita na literatura anglo-saxônica à questão do estabelecimento do objeto na disciplina, da seguinte forma: "a relação 
de uma medida da ocorrência a um determinante, ou uma série de determinantes, é denominada de relação ou função da ocorrência. Tais relações são, em geral, o objeto de investigação da epidemiologia" (MIETTINEN, 1985, p. 6). Esta proposta é metodologicamente fundada em princípios de rigor e coerência interna, propiciando uma conexão lógica entre seus princípios e aplicações imediatas às técnicas de análise epidemiológica mais usadas modernamente.

Contrariamente ao que se encontra semi-implícito nos manuais da área, o objeto da Epidemiologia não pode ser definido como um objeto probabilístico, porque o que constitui sua validade conceitual não é validado por modelos de probabilidade (VINEIS, 1999). O objeto epidemiológico, nessa perspectiva, pode ser mais bem compreendido enquanto um objeto-resíduo. O método epidemiológico opera avaliando, em primeiro lugar, proposições determinísticas (sob a forma de hipóteses causais), em confronto com distribuições teóricas estocásticas. Caso tais proposições sejam satisfatoriamente explicadas por um modelo de distribuição aleatória (em geral chamado de hipótese nula), rejeitarse-á a hipótese do estudo. Em outras palavras, o que não é explicado pela estocasticidade (modelo de distribuição aleatória), o é pela determinação atribuída como epidemiológica. A Estatística, nesse sentido, não teria uma função explicativa, e sim uma função de "depuração do objeto", o que implica dizer que o objeto epidemiológico constitui-se em resíduo de objetos probabilísticos, operando com um tipo de determinação sui-generis.

Os modelos operados no paradigma dominante na epidemiologia moderna são construídos como modelos de risco. O termo "risco" designa diretamente o objeto-resíduo, enquanto probabilidade de adoecer que se desvia das probabilidades puramente aleatórias. A fundamentação da regra de prova nesse paradigma seria a inferência estatística, utilizada como método auxiliar do teste de hipóteses. O emprego mais simples e imediato desse método pode ser reconhecido na operação quase banal de se desconhecer como fator de risco aquele que, apesar de expresso por uma medida de associação de grande magnitude, refere-se a um nível de significância estatística convencionado como insatisfatório (ALMEIDA-FILHO, 1992, p. 101).

A Estatística justificaria uma expectativa de generalização por procedimentos indutivos (apesar da crítica da epidemiologia popperiana), através de um conjunto condicional de probabilidades de adoecer que não seriam explicáveis por modelos aleatórios. Analisando comparativamente os usos da indução, deve-se distinguir dois tipos de generalização: a predição propriamente 
dita, no sentido de uma expectativa de recorrência no tempo, em relação a casos novos esperados, e a predição equivalente à extrapolação para casos e eventos não incluídos na amostra ou população estudada. Em relação a esta última, temos uma inferência de natureza "horizontal", no sentido de amplitude populacional, e uma inferência "vertical", buscando a convergência para os casos individuais.

A proposição de risco como conceito fundamental do campo científico da Epidemiologia repousa sobre três pressupostos básicos: o primeiro é a identidade entre o possível e o provável, ou seja, que a possibilidade de um evento pode ser reconhecida na sua probabilidade de ocorrência. Essa probabilidade se constitui como unidimensional, variável e, por extensão, quantificável. Dessa forma, o conceito de risco traz na raiz uma proposta de quantificação dos eventos da saúde/doença (MACMAHON; PUGH, 1970; LILIENFELD, 1976).

O segundo pressuposto consiste na introdução de um princípio de homogeneidade na natureza da morbidade, ou seja, as particularidades dos eventos se retraem perante uma dimensão unificadora, resultando em uma unidade dos elementos de análise propiciada pelo conceito de risco. As diferenças expressas na singularidade dos processos concretos saúde-doença desaparecem no conceito unidimensional de risco e suas propriedades, permitindo aproximações e apropriações próprias do discurso científico epidemiológico (ALMEIDA-FILHO, 2000). As incidências de distintos eventos de saúde ou doença, indicadores dos respectivos riscos, entendidos como probabilidades de ocorrência, são postas em um mesmo registro.

Em terceiro lugar, destaca-se o pressuposto da recorrência dos eventos em série, implicando a expectativa de estabilidade dos padrões de ocorrência seriada dos fatos epidemiológicos. Através desse pressuposto, pode-se então justificar a aplicação do conceito de risco em modelos de prevenção, propondose o conhecimento dos seus determinantes para intervir no seu processo, buscando-se a prevenção do risco (MACMAHON; PUGH, 1970).

Tais pressupostos revelam claramente o caráter indutivista da Epidemiologia (BUCK, 1975; SUSSER; SUSSER, 1996), dadas a fundamentalidade e a natureza das expectativas generalizadoras embutidas no conceito. Desta forma, o risco é produzido no campo da Epidemiologia pela observação sistemática e disciplinada de uma série de eventos. Enquanto conceito, o risco opera pela via da predição, com base no terceiro pressuposto. 
Refletindo sobre o caráter da predição no discurso epidemiológico, constatamos basicamente dois sentidos distintos, que concedem ao conceito de risco a ambigüidade que é própria do projeto da Epidemiologia enquanto campo discursivo científico.

Por um lado, é possível a predição no tempo, componente propriamente antecipatório do conceito de risco. Quando enunciamos o risco de ocorrência de uma doença $\mathrm{D}$ em uma dada população, empregamos uma série sucessiva de observações pregressas (mensurações tomadas, na melhor das hipóteses, em uma série temporal padronizada), para fazer uma predição do passado (por suposto conhecido) para o momento presente ou mesmo para o futuro, aplicada à população objeto daquela série de observações. Temos aqui o emprego do risco enquanto preditor temporal, ou "preditor verdadeiro".

Por outro lado, na Epidemiologia observa-se também o uso do componente indutivo do risco para instrumentalizar pseudopredições, ou predições no espaço. Neste segundo caso, em vez de uma mesma população em momentos distintos no tempo, extrapola-se uma série finita de observações em populações estudadas para populações não observadas. Isso quer dizer que, a partir do conhecimento da incidência da doença $\mathrm{D}$ em um conjunto de populações conhecidas, pretende-se "predizer", com o auxílio de testes estatísticos, intervalos de confiança, média de incidências, ou qualquer outro quantificador matemático, qual será o risco da doença $\mathrm{D}$ na população em geral, ou em grupos populacionais não incluídos na série observada. Trata-se, nesse caso, do emprego do risco como um pseudopreditor, ou "preditor horizontal".

Essa ambigüidade é a principal característica do uso epidemiológico do conceito de risco: um preditor simultaneamente temporal e espacial, ou, mais rigorosamente, como preditor e pseudopreditor. Esse conceito de risco permite o rompimento dos limites temporais e dos limites geográficos do processo de produção do dado, dotando o conhecimento epidemiológico de propriedades generalizadoras nem sempre legitimadas pela lógica que o consubstancia.

E onde se situa o risco no discurso epidemiológico? Para além e para fora do sujeito, o risco é localizado no âmbito da população, produzido ou atribuído no âmbito dos coletivos humanos. Risco é enfim uma propriedade das populações e a sua referência legítima será exclusivamente coletiva (HAYES, 1992). Nos primórdios da constituição da Epidemiologia enquanto ciência, havia uma proposta implícita de conceituação do "risco absoluto" - daí a derivação da idéia de "risco relativo" (LILIENFELD, 1976). Apesar de equivocadamente tomado 
como expressão individual em alguns manuais (JENICEK; CLEROUX, 1985), o risco absoluto sempre teve como referência fundamental o coletivo populacional.

A idéia de risco relativo permite a construção do conceito derivado "fator de risco". Em algumas das aplicações específicas do discurso epidemiológico, mais forte em certas subáreas pela constituição de um campo semântico próprio, nota-se uma incoerência no mínimo curiosa. Trata-se da transferência para o campo epidemiológico (formação discursiva de base científica e, portanto, com pretensões de coerência, precisão e consistência), daquela inconsistência que se observa no discurso social comum de confusão de designação entre risco e fator de risco, ou entre efeito e sua causa potencial. Ora, se no campo epidemiológico, risco é predição, fator de risco será então um preditor de uma predição, ou "risco de risco". Por meio dessa operação, terminase atribuindo à idéia de fator de risco o estatuto do conceito de risco propriamente. Na subárea da Saúde Ocupacional, por exemplo, está cada vez mais estabelecido chamar de "risco ocupacional" fatores de risco presentes no ambiente ou no processo de trabalho. Trata-se de interessante exemplo de como uma inconsistência em um dado discurso pode tornar-se incoerência em outro campo discursivo.

A presença de inconsistências dessa natureza é fatal para a produção de argumentos no interior de um dado campo científico, na medida em que a diferenciação entre conceitos, mesmo estreitamente correlacionados, cumpre uma função lógica de operar heterogeneidades necessárias. Dessa forma, o processo heurístico da investigação fica inviabilizado. Por outro lado, o discurso é soberano e está continuamente se instituindo, estabelecendo-se, e soluções deverão aparecer a fim de superar a momentânea falta de coerência no processo de auto e heteroconstituição do campo discursivo. Disso poderá resultar a fabricação de novos conceitos, até mesmo uma outra (nova) linguagem de maior precisão.

\section{Aberturas paradigmáticas}

Considerando a natureza simbólica, complexa e singular da relação entre saúde-doença-cuidado e processos sociais, propomos que o conceito de Risco terá algum futuro no campo da ciência, caso seja reconstruído dentro da teoria da complexidade, empregando lógicas para-consistentes (borrosidade e contingência). 
Alguns teóricos da complexidade (RUELLE, 1991; PERCIVAL, 1994) privilegiam os componentes analíticos formais que poderiam justificar a denominação genérica de teoria do caos ou da não-linearidade. Lorenz (1993), um dos fundadores dessa perspectiva, sugere que a teoria do caos constitui um supersistema teórico baseado principalmente nos conceitos de não-linearidade, complexidade e fractalidade. Nas suas versões mais aplicadas, tais propostas se apresentam quase como um "neo-sistemismo", atualizando e expandindo algumas posições da teoria dos sistemas gerais, que havia alcançado certa influência no panorama científico dos anos 1950 e 60 (VON BERTALANFFY, 1962). Por esse motivo, a terminologia "teoria dos sistemas dinâmicos" tem sido empregada com certa freqüência para designar os modelos complexos gerados no contexto de propostas de um paradigma científico alternativo (ATLAN, 1981; PRIGOGINE; STENGERS, 1986).

No campo da Saúde Coletiva, vários autores têm defendido o emprego de modelos de complexidade em geral para abordar diferentes questões de pesquisa: Attinger (1985) já propunha a análise de políticas de saúde a partir de modelos sistêmicos dinâmicos, desde uma perspectiva teórica da complexidade, capazes de integrar os níveis micro e macro e as transformações dos sistemas de saúde. Castellanos (1990) e Almeida-Filho (1990), independentes, mas simultaneamente, sistematizaram propostas equivalentes e complementares de uso dessas novas abordagens paradigmáticas para a construção metodológica do objeto da pesquisa epidemiológica. Tais propostas vêm sendo ampliadas e difundidas com o objetivo de fomentar uma produção científica concreta, visando a efetivamente alimentar um possível paradigma novo (SCHRAMM; CASTIEL, 1992; CASTIEL, 1994; KOOPMAN, 1996; SUSSER; SUSSER, 1996a; PHILIPPE, 1998; BREILH, 2004; ALMEIDA-FILHO, 2000, 2006).

Para avaliar as possibilidades de uso de modelos complexos para análises de risco em Epidemiologia, precisamos antes rever brevemente alguns princípios do que se tem denominado de teoria da complexidade. No vigamento central da teoria dos sistemas, encontram-se as formas elementares de determinação em qualquer modelo explicativo dado:

a) Composição - articulação de partes $(\mathrm{A}+\mathrm{B})$, componentes de um todo (D). Isto corresponde a uma metáfora trazida da noção de síntese em Química. A formalização matemática é a simples soma de elementos: A + B = D.

b) Variação - trata-se da principal representação de causalidade em ciência, enquanto metáfora trazida do campo da dinâmica em Física. O modelo 
básico desta forma elementar de determinação é o seguinte: um fator x, agindo em uma determinada situação de saúde $\mathrm{S}$, produz o resultado R (significando Risco, para nossos propósitos). A formalização matemática é o caso mais simples de uma equação de função, com um único termo: $\mathrm{R}=f(\mathrm{X})$. Aqui temos a forma elementar do objeto epidemiológico Risco, em sua apresentação convencional.

c) Emergência - processo de sobredeterminação (FREUD, 1893) que descreve o aparecimento de algo que, como tal, não estava antes no sistema, considerando-se múltiplas e dinâmicas determinações causais. Uma descontinuidade na dinâmica do sistema, gerando o que uma variante nova do cálculo chama de "catástrofes", de acordo com Thom (1985). Posto que nenhuma formalização encontra-se disponível para essa modalidade de ocorrência, $\mathrm{R}$ emerge de fontes desconhecidas de determinação: $*=>\mathrm{R}$. Trata-se aqui, em sua forma mais elementar, de um resgate da categoria aristotélica da contingência.

Nesse jogo de definições, "simplicidade" resulta de processos de analysis, i.e., o sistema é descrito desdobrando-o em suas formas elementares mais simples de determinação. Isto é equivalente à redução cartesiana de processos sistêmicos e relações às formas elementares de determinação. A transição de simplicidade para complexidade não é linear e direta, e passa pela "complicação" como um nível superior imediato.

O que significa complicação? Vejamos um "modelo complicado de primeira ordem", que, entre outras coisas, demonstra que multiplicar os elementos de um determinado sistema não é suficiente para nele "introduzir" complexidade. Consideremos a variação multifatorial de $\mathrm{S} P \mathrm{R}$, determinada por fatores $\mathrm{x}_{1}$ a $\mathrm{x}_{\mathrm{n}}$. A formulação matemática é simplesmente a notória equação de regressão linear múltipla generalizada $\mathrm{R}=\mathrm{f}\left(\mathrm{x}_{1}+\mathrm{x}_{2} \ldots \mathrm{x}_{n}\right)$. Este modelo também pode ser tomado como uma apresentação vívida da definição epidemiológica de multicausalidade que incidentalmente é o resultado não de complexidade, mas de complicação na modelagem. Sistemas desse tipo se encontram longe da complexidade, porque neles não há qualquer hierarquia nem qualquer consideração da diversidade complexa da realidade concreta.

Vejamos agora um "modelo complicado de segunda ordem", com variação em dois níveis, matematicamente descrito por um sistema de equações de regressão linear: $\mathrm{R}=\mathrm{f}\left(\mathrm{x}_{1}+\mathrm{x}_{2} \ldots x_{n}\right) ; \mathrm{x}_{1}=\mathrm{f}\left(x_{n}\right)$. Podem ser introduzidos passos no modelo, que assim se torna hierarquicamente organizado. Porém, 
todas as interconexões entre seus componentes são do mesmo tipo, fazendo dele um sistema monótono, sem respeitar a diversidade de parâmetros. Esta é outra faceta do reducionismo, porque essa modelagem da realidade reduz a diversidade dos nexos que existem em qualquer fenômeno ou processo a uma série de relações unificadas. Um exemplo imediato desse tipo de modelo na teoria epidemiológica dos riscos é a clássica "teia da causalidade" (KRIEGER, 1994).

A introdução de formas elementares de determinação diversas num mesmo modelo define-o como "modelo complicado de terceira ordem". Nessa família de modelos, vemos uma aproximação intuitiva da articulação de formas diferentes de determinação, inclusive a transformação de componentes em fatores, pela definição de variáveis proxy. Para construir e operar modelos desse tipo, metodologias inter e transdisciplinares são definitivamente necessárias. Objetos desse tipo podem se tornar modelos prototípicos para a integração desejada entre ciências sociais (por exemplo, para os processos macrossociais representados como composições na base do modelo), lógica e semântica (justifica a anamorfose que une o nível básico ao submodelo de fator) e ciências clínicas ou de saúde (responsáveis pela modelagem do resultado de saúde ou risco R). A formulação matemática possível funda-se mais em lógica do que em cálculo aplicado. Porém, o potencial dessa família de modelos de apreender processos da realidade ainda é considerado insatisfatório, por causa de sua direcionalidade. Realmente, todas as relações internas são convergentes para o resultado, assim considerado como finalização (desenlace ou outcome) dos processos. Apesar do poder heurístico superior desse modelo vis-à-vis os modelos precedentes, ainda operam no domínio da complicação (mas não da complexidade), dado que nele não se encontra qualquer tratamento possível das mudanças ou fenômenos tempo-dependentes.

Complexidade relaciona-se à dialética movimento-permanência. Nenhum dos modelos anteriores, mesmo aqueles sofisticados e articulados, considera o fluxo do tempo. Até mesmo em suas versões mais sofisticadas, ainda se mostram reducionistas monótonos, ou finalísticos e, acima de tudo, aprendem a realidade complexa por congelamento dos seus processos, quer dizer, por paralisia de sua característica mais básica, a natureza dinâmica do evento. Um sistema, mesmo o mais complicado de todos, que sempre converge a uma mesma produção fixa, não é um sistema dinâmico. Por isso é que a noção de retroalimentação se tornou crucial para a teoria dos sistemas. Da mesma forma, isto explica por que a idéia de repetição, e não reprodução, é fundamental para definir não-linearidade em sistemas dinâmicos. 
Vejamos um "modelo complexo de primeira ordem". Trata-se de um modelo plural (com diversidade de formas de determinação), hierárquico, multinível e não-direcional, construído a partir da primeira definição de complexidade como sistematicidade dinâmica. Nesse modelo, o output no tempo 1 significa input no tempo 2. Por outro lado, ainda é um modelo discreto (baseado-em-limites, feito de componentes isolados) e não sensível-a-contexto. Modelos desse tipo são suscetíveis de descrições matemáticas, baseadas em sistemas de equações diferenciais. Por permitir "retroação conservadora" (ou homeostase), estes modelos eram antes considerados como exemplos paradoxais de complexidade linear. Porém logo a crescente capacidade computacional permitiu aos investigadores descobrir caos em equações bastante simples, como as equações para predição meteorológica, de Lorenz (1993). Para nosso tema, modelos complexos de risco, isto pode ser demonstrado de maneira muito direta, usando a incidência de uma doença $\mathrm{D}$ como exemplo.

Consideremos um único ciclo de avaliação de um dado sistema epidemiológico. Nesse caso, $\mathrm{R}_{\mathrm{n}}$ (risco no tempo 1 ) é diferente de $\mathrm{R}_{\mathrm{n}+1}$ (risco no tempo 2). Dado que a medida de R é a incidência I, uma relação dependente do tamanho de uma população $\mathrm{P}$, considere-se também que $\mathrm{P}_{\mathrm{n}}=\mathrm{P}_{\mathrm{n}+1}$, por conseguinte fixando o parâmetro de mudança populacional. Este é o modo mais simples de representar a iteração desse tipo particular de sistema dinâmico. A meta última da pesquisa epidemiológica realmente consiste em medir a variação do "volume" de D (conjunto de doentes entre expostos) no tempo, o que significa basicamente avaliar $\mathrm{D}_{\mathrm{n}} \mathrm{P} \mathrm{D}_{\mathrm{n}+1}$. Aplicações desse modelo para análise de risco em epidemiologia têm sido bastante frutíferas, especialmente no que se refere a epidemias de doenças infecciosas.

O clássico modelo SEIR (Suscetibilidade-Exposição-InfecçãoRecuperação) já representava uma tentativa de descrever a dinâmica epidemiológica das doenças infecciosas, através de um sistema de equações diferenciais, ainda dentro de uma expectativa de modelagem linear da descontinuidade (ANDERSON, 1982). Segundo Halloran e Struchiner (1991), a noção de "evento dependente", proposta por Sir Ronald Ross, em 1910, já antecipava a concepção de não-linearidade como iteração de efeitos em um sistema dinâmico. Grenfell, Bolker e Kleckowski (1995), empregando técnicas de simulação parametrizada, desenvolveram uma interessante demonstração da ocorrência de não-linearidade em modelos SEIR submetidos a diferentes intervalos de sazonalidade. Recentemente, Koopman e Longini (1994) apresentaram um modelo teórico da associação entre níveis de exposição 
domiciliar ao mosquito e risco de infecção por dengue no México, em que a análise epidemiológica convencional, linear, de base individual, revelou medidas relativamente estáveis de não-associação. Quando se incorporou ao modelo um fator de dependência da exposição como resultado da incidência (ou seja, uma taxa de "realimentação" da epidemia), observou-se um aumento não-linear da taxa de infecção.

Dentre as concepções menos conhecidas das novas abordagens paradigmáticas associadas à teoria da complexidade, abrem-se perspectivas de ruptura com a lógica formal ainda hegemônica na ciência contemporânea. Nesse registro, situa-se a "teoria dos conjuntos borrosos" [fuzzy set theory], proposta por Lofti Zadeh no início da década de 1960 (MCNEILL; FREIBERGER, 1993). Trata-se de uma abordagem crítica das noções de limite e de precisão, essenciais à teoria dos conjuntos que funda a analítica formal da ciência.

Essa concepção lógica rompe com a lógica clássica que define os fundamentos epistemológicos do conhecimento com base nos princípios da identidade, da não-contradição e do terceiro excluído (COSTA, 1980). Como corolário da ruptura proposta, haveria três modalidades de incerteza - a contradição, a confusão e a ambigüidade - não passíveis de formalização lógica e matemática, portanto, fora dos limites da racionalidade científica clássica. A estas, acrescente-se a "borrosidade" [fuzziness], propriedade particular dos sistemas complexos no que se refere à natureza arbitrária dos limites infrasistêmicos impostos aos eventos (unidades do sistema) e ao próprio sistema (ZADEH, 1971), em suas relações inter-sistêmicas com outros sistemas, com os super-sistemas (contextos) e com os respectivos observadores.

Em primeiro lugar, a teoria dos conjuntos borrosos implica uma crítica radical à noção de evento como uma fragmentação arbitrária dos processos de transformação e dos elementos dos sistemas dinâmicos. Alguns conceitos operativos do campo da saúde, como doença e risco, são exemplares dessa ontologia conjuntista da ciência convencional (ALMEIDA-FILHO, 2000). Desta maneira, impõe-se uma delimitação precisa e de certo modo aberta, onde efetivamente ocorre uma fluidez dos limites espaço-temporais dos elementos de um dado sistema, que podemos denominar de Borrosidade 1.

Segundo, a consideração da lógica borrosa supõe uma recuperação da contextualização (ou referencialidade) como etapa crucial do processo de produção de conhecimento. Neste caso, borram-se os limites externos do 
sistema, ou seja, a interface entre os sistemas entre si e destes com o contexto, ou os supersistemas que os incorporam, conformando o que podemos chamar de Borrosidade 2.

Por último, a crítica da noção de limite implica também um questionamento da categoria epistemológica da objetividade, retomando o clássico problema do observador como efeito de uma Borrosidade 3. Neste caso, é atraente a referência, por simples analogia, à delimitação entre sujeito e objeto no processo da pesquisa. Paradigmática desta categoria de borrosidade será certamente a questão fundamental dos limites da percepção humana enquanto produto de "correlações senso-efectoras" de um organismo dito observador enredado em espaços perceptuais compartilhados com os objetos observados (MATURANA; VARELA, 1984).

No campo da saúde, praticamente inexistem aplicações da noção de borrosidade, apesar da sua inegável aproximação ao problema dos diagnósticos superpostos ou comorbidade, conforme assinalado por Mezzich e Almeida-Filho (1994), e à questão da natureza borrosa da definição tanto de exposição quanto de risco no referencial epidemiológico (COSTA-CAPRA, 1995). Uma interessante atualização sobre o assunto foi recentemente publicada por SadeghZadeh (2000), destacando justamente os usos teóricos e práticos da lógica fuzzy na pesquisa sobre saúde-doença.

Vejamos agora um bom exemplo de aplicação da idéia de conjuntos borrosos proveniente da epidemiologia, vertente mais flagrantemente quantitativa da Saúde Coletiva. Massad e Struchiner (1996) propuseram traduzir nos termos da lógica dos conjuntos borrosos os indicadores epidemiológicos de associação, aplicando-os principalmente à análise de risco em estudos ambientais. Como vimos acima, os estimadores de risco relativo mais usuais da Epidemiologia são definidos como uma razão de probabilidades condicionais à exposição a um suposto fator de risco, em que o estimador de risco $\mathrm{R}$ representa uma probabilidade $\mathrm{p}$ de ocorrência de uma doença $\mathrm{D}$, dada uma exposição $\mathrm{E}$, ou seja, $\mathrm{p}(\mathrm{D} \mid \mathrm{E})$. Entretanto, no cenário de uma lógica borrosa, esses indicadores podem ser expressos em termos de possibilidades condicionais, tanto no sentido de níveis de exposição quanto de gravidade da doença. Para isso será necessário estimar funções de distribuição de possibilidades equivalentes a distintos graus de pertinência associados a cada subconjunto borroso, resultando em modelos lingüísticos de inferência borrosa. 
$\mathrm{Na}$ formulação original de Zadeh, o criador da fuzzy logic, como sabemos, a função $\mathrm{F}$ de pertinência $R(x, y)$ de uma relação $\mathrm{R}$ em um conjunto borroso A é dada por operadores de inferência do tipo max: $V$ - min: $L$, em que $\mathrm{F}(\mathrm{y}) V x[\mathrm{~A}(\mathrm{x}) L \mathrm{R}(\mathrm{x}, \mathrm{y})$. Aplicando estes parâmetros, de acordo com Massad e Struchiner (1996), é possível definir uma Fuzzy Odds Ratio (FOR), como a razão entre a possibilidade condicional de desenvolvimento de certa doença cuja gravidade é $\mathbf{d}$, dado que o indivíduo seja exposto a um certo nível do fator ambiental e, e a possibilidade de que a mesma doença com gravidade $\mathbf{d}$ se desenvolva, dado que o indivíduo não seja exposto ao fator ambiental.

Apesar do estado ainda incipiente de aplicação da lógica borrosa no campo da saúde, além das análises de graus e superposição de exposição e gravidade especificamente diferenciada, são evidentes os usos potenciais dessa abordagem nos processos de tomada de decisão na subárea de gestão e administração em saúde. Ainda por desenvolver, estariam aplicações da lógica borrosa nos sistemas de produção estruturada de diagnósticos, principalmente para tratar dos fenômenos da co-morbidade e dos diagnósticos múltiplos.

\section{O futuro do conceito de risco}

Risco é mais do que um conceito interdisciplinar: precisamos nos preparar para cada vez mais compreendê-lo e construí-lo como um conceito indisciplinado (CASTIEL, 1997). No percurso argumentativo deste ensaio, identificamos e avaliamos os pressupostos filosóficos das seguintes formas de apresentação do conceito: a) "Risco" como perigo latente ou oculto no discurso social comum; b) "Risco Individual" como conceito da Clínica; c) "Risco Populacional" como conceito epidemiológico senso estrito; d) "Risco Estrutural", nos campos da Saúde Ambiental/Ocupacional.

O conceito de Risco necessita atualizar-se, incorporando a dimensão contingente dos processos de ocorrência de problemas de saúde em populações humanas. O futuro do conceito de risco dependerá da sua capacidade de articular-se aos desenvolvimentos conceituais e metodológicos deste novo campo ideológico, conceitual e metodológico que tem sido denominado de Saúde Coletiva, contribuindo com modelos teóricos e estratégias metodológicas capazes de abordar objetos complexos emergentes. Nesse sentido, propomos incorporar mais uma definição à lista dos conceitos de Risco acima: e) "Risco Contingencial", operador do recém-constituído campo de práticas da Promoção da Saúde. 
A idéia de um campo geral de práticas chamado de Promoção da Saúde, contendo tanto a Prevenção quanto a Proteção e a Promoção (senso estrito) da saúde individual e coletiva, supõe um repertório social de ações preventivas de morbidade (riscos, doenças etc.), protetoras e fomentadoras da salubridade, que de certo modo contribui para a redução dos sofrimentos causados por problemas de saúde-doença na comunidade. Isso determina uma integração teórica e filosófica da rede de conceitos correlatos à saúde (vida, risco, doença, cuidado) ao conjunto de práticas discursivas e operacionais dos novos campos de saberes e de práticas que cada vez com mais intensidade e freqüência se formam em torno do objeto Saúde. Com esse objetivo, os conceitos de Risco e as práticas que lhe correspondem no campo da Saúde podem ser reunidos em três grupos:

1. Risco como indicador de causalidade (ou resíduo da probabilidade). Trata-se de reconhecer e reafirmar sua base indutiva, frequientista, fisheriana, a partir do referencial exposto na terceira parte deste ensaio. Esse conceito particular de Risco subsidia modelos de Prevenção de doenças ou eventos mórbidos, com as seguintes variantes: (a) modelos de prevenção individual (conceito clínico de Risco); (b) modelos de prevenção populacional (Teorema de Rose).

2. Risco como perigo estruturado. Tal conceito subsidia largamente modelos de intervenção nos campos da Saúde Ambiental e Ocupacional (OPAS, 1976). Nesse caso, é preciso explorar sua base dedutiva, descritiva, estrutural, tarefa que evidentemente extrapola os objetivos do presente ensaio.

3. Risco como emergência. Trata-se, nesse caso, de explicitar a base filosófica da contingência, articulada como processos de emergência em modelos de complexidade. Este conceito subsidia modelos de: a) Promoção da Saúde; b) Vigilância em Saúde.

O quadro abaixo ilustra os principais elementos conceituais envolvidos nessa articulação:

\begin{tabular}{|c|c|c|c|c|}
\hline MODELOS & $\begin{array}{c}\text { TIPOLOGIAS DE } \\
\text { INTERVENÇÃO }\end{array}$ & REGISTROS & MODAIS & ESTRATÉGIAS \\
\hline Causalidade & Modelagem & Simbólico & Necessidade & PREVENÇãO \\
\hline Controle & Experimento & Real & Impossibilidade & PROTEÇÃO \\
\hline Estrutura & Regulação & Imaginário & Possibilidade & PRECAUÇÃO \\
\hline Emergência & Vigilância & Objeto a & Contingência & PROMOÇÃO \\
\hline
\end{tabular}


O quadro a seguir ilustra os principais elementos de atuação comparativos dessas estratégias:

\begin{tabular}{|c|c|c|c|c|}
\hline ESTRATÉGIAS & DISPOSITIVOS & SIGNOS & ALVOS & AÇÕES \\
\hline PREVENÇÃO & Riscos & Fatores de risco & Grupos de risco & $\begin{array}{c}\text { Redução } \\
\text { Remoção }\end{array}$ \\
\hline PROTEÇÃO & Marcadores & Defesas & $\begin{array}{c}\text { Sujeitos } \\
\text { Comunidades }\end{array}$ & $\begin{array}{c}\text { Imunização } \\
\text { Reforço }\end{array}$ \\
\hline PRECAUÇÃO & Sensores & Eventos sentinela & $\begin{array}{c}\text { Ambientes } \\
\text { Cenários }\end{array}$ & $\begin{array}{c}\text { Legislação } \\
\text { Controle }\end{array}$ \\
\hline PROMOÇÃO & Monitores & $\begin{array}{c}\text { Tendências } \\
\text { Padrões }\end{array}$ & $\begin{array}{c}\text { Ambientes } \\
\text { Produtos }\end{array}$ & $\begin{array}{c}\text { Monitoramento } \\
\text { Fomento }\end{array}$ \\
\hline
\end{tabular}

Os dispositivos, signos e ações apontados no esquema são característicos de cada estratégia, porém não se propõe aí uma relação de exclusividade, nem biunívoca, ponto a ponto. Para uma compreensão mais clara dos quadros propostos, explicitaremos, a seguir, seus termos.

A estratégia de Prevenção em Saúde há muito se converteu à ordem da necessidade, assentada no modelo da causalidade e cuja intervenção mais específica seria a modelagem da realidade. Como vimos, Aristóteles define o real como aquilo que é. Se o real se caracteriza como o que já estava ali, a realidade, ou melhor, as realidades são construídas para tentar dar conta deste real que não fala, antes se mostra como limite à simbolização. O regime da necessidade é solidário ao registro simbólico, de acordo com a formulação que faz Lacan ao retomar os termos modais de Aristóteles. Trata-se, na necessidade humana, daqueles eventos imprescindíveis ao mundo de linguagem, pois, ao constituir-se como ser de linguagem, o humano instaura um movimento peculiar: o simbólico (discurso humano) separa a realidade do real, ao promover, pela mediação da palavra, uma cisão entre coisa e símbolo. Lacan descreve este registro do simbólico sob a égide da necessidade como "aquilo que não cessa de se escrever".

Por outro lado, a Proteção à Saúde como estratégia, por vários ângulos de análise, é logicamente impossível, apesar de historicamente ter sido construída como campo de prática plausível. Seu modelo é o controle e a intervenção requerida, o experimento. Tal modalidade - o impossível - deve ser tomada em sua estrutura lógica, não significando com isso que não exista. Apenas que controle e experimento não são realidades em si, mas realidades lingüísticas 
não-encontráveis nas condições efetivas da pesquisa ou da intervenção; tal como os eventos contingentes, são realizados e somente então reconhecidos por seus efeitos. Em termos lógicos, "o que não cessa de não se escrever" se impõe (não cessa) e, ao mesmo tempo, por escapar ao simbólico, não se escreve. Rigorosamente, um experimento nunca pode ser reproduzido, é único, podendo, sim, ao ser replicado, constituir série. Ademais, tal replicação nunca se dá conforme o planejado, posto que a situação do laboratório não tem com a vida outra relação senão de verossimilhança. É por esse motivo que Lacan define o Real, registro do impossível lógico, como "o que não cessa de não se escrever"; por mais que ensaiemos, jamais a realidade do experimento corresponderá ao real do evento.

A possibilidade, modo lógico da estratégia de Precaução, é o registro referente ao imaginário que, longe de ter um caráter negativo de algo imaginado ou ilusório, como comumente se diz, só pode ser pensado no entrelaçamento dos três níveis, juntamente com simbólico e real. Na formalização proposta por Lacan, é "o que cessa de se escrever", aquilo que pode parar de ser requerido. É o imaginário que dá consistência ao mundo humano, povoando com Cenários as possibilidades de existir na linguagem. Assim, retomando os Teoremas de Gödel, lembremos que a consistência dos limites - impostos por cenários imaginados - não é incompatível, pelo contrário, com a abertura de possíveis e inimagináveis medidas de Precaução contra riscos à saúde. Entretanto, é esta tela imaginária, este limite, com sua função ao mesmo tempo formadora e alienante, que organiza não o mundo em si, mas o mundo em questão. A utilização das estratégias de Precaução no campo da Saúde (GRANDJEAN, 2004), como construção de cenários antecipatórios possíveis a danos existentes ou projetados, desempenha um papel não-negligenciável de também antecipar, e nesse caso conter, reações de pânico ou inquietação generalizados que muitas vezes o imaginário social desenvolve frente ao desconhecido.

Por fim, associamos a estratégia de Promoção à Saúde aos modelos de imprevisibilidade de eventos, incorporados nas teorias da complexidade, como emergência, e na filosofia, como contingência. De todas as modalidades lógicas, esta é, seguramente, a que mais resiste a uma apreensão direta de sentido; não à toa, Lacan a descreveu como "o que cessa de não se escrever". Em outras palavras, trata-se da ocorrência de um evento que faz cessar, interrompe bruscamente, um estado anterior, mas que, em conformidade com o real, não se escreve como fato. Poderá ser, retroativamente, integrado à cadeia significante como suporte para estratégias fomentadoras de ações globais de 
supervisão e vigilância, como as práticas atualmente denominadas de Promoção da Saúde, destinadas a detectar, compreender e significar emergênciasocorrências-contingências para, com isso, reconhecer (para fazer cessar seus efeitos) eventos similares futuros (LEVY, 1996).

Como o nome indica, os conceitos de emergência ou contingência articulam acontecimentos dos quais podemos apenas constatar efeitos e, na impossibilidade de propor medidas de ação retroativas, indicar formas precaucionárias de base analógica. Em geral, são acontecimentos desencadeados por fatores múltiplos e interconectados, estruturados em redes abertas, o que impossibilita estabelecer, entre eles, relações lineares de causalidade. Na esfera dos acontecimentos contingentes, pensamos ser de especial valor, como tipologia de intervenção mais adequada, a utilização de teoria de redes como desenho não somente de explicação, no caso, da sobredeterminação de fatores causais, como também de desenho metodológico para programas de promoção da saúde.

\section{Comentário final}

O presente conjunto de anotações constitui um dispositivo esquemático de síntese teórica provisória, por definição insuficiente para dar conta da complexidade dos fenômenos, processos e problemas da saúde-doença-cuidado, até o momento expressos pelo conceito de risco. No espírito introdutório deste ensaio, deixamos em suspenso, para posteriores desdobramentos, dois importantes itens: (i) a discussão referente ao objeto a, formalização efetuada por Lacan para representar o vazio da estrutura do ser de linguagem, vazio necessário e impossível de ser apreendido e, por isso, apresentado por meio de uma letra minúscula; (ii) o rico potencial de conceituação representado pelo emprego de teorias de redes ou grafos (NEWMAN; BARABÁSI; WATTS, 2006) como dispositivos heurísticos para a reconstrução teórica do "Risco" como tema/problema. Não obstante os seus limites, esperamos que estas reflexões, ainda preliminares, sejam úteis para fazer avançar o necessário debate teórico-conceitual em Saúde.

Em conclusão, qualquer projeto conseqüente de transformação da situação de saúde das populações vai requerer conceitos destacados pela diversidade de sua extração teórica. Portanto, será imperativo desenvolver métodos caracterizados pela pluralidade das técnicas de investigação e análise, propiciando compreensões totalizadoras dos sistemas históricos e formulações 
de práticas discursivas e operativas efetivamente capazes de interferir no espaço social da Saúde Coletiva. Na expectativa de avanço e aprofundamento do debate conceitual em torno do conceito de risco e sua articulação no campo de práticas da Saúde, será enfim fundamental uma postura crítica capaz de explicitar implicações e sobredeterminações políticas e econômicas da produção do conhecimento científico e das transformações históricas dos processos relativos à vida, à saúde, ao sofrimento e à morte nas sociedades humanas.

\section{Referências}

ALMEIDA-FILHO, N. A ciência da saúde. São Paulo: Hucitec, 2000. . A clínica e a epidemiologia. Rio de Janeiro: ABRASCO, 1992.

A saúde e o paradigma da complexidade. Cadernos IHU, São Leopoldo, v. 4, n. 15, p. 4-45, 2006.

. Paradigmas em epidemiologia. IN: CONGRESSO BRASILEIRO DE EPIDEMIOLOGIA, 1. Epidemiologia e Desigualdade Social: os desafios do final do século. Anais... Campinas, 2 a 6 de setembro de 1990.

ANDERSON, R. Population dynamics of infectious disease: theory and application. London: Chapman and Hall Press, 1982.

ARISTÓTELES. Organon. Tradução, prefácio e notas de Pinharanda Gomes. Lisboa: Guimarães Editores, 1985.

ATLAN, H. Entre le crystal et la fumée. Paris: Seuil, 1981.

ATTINGER, E. Dynamic modeling and health policy research. Genebra, 1985 (Technical Papers WHO/RPD/SOC).

AYRES, J. R. Sobre o risco: para compreender a Epidemiologia. São Paulo: Hucitec, 1997.

BADIOU, A. La verdad: forzaje e innombrable. Acontecimiento: revista para pensar la política. Buenos Aires, ano III, n. 6, 1993.

BECK, U. La Sociedad del Riesgo. In: BECK, U. et al. (Orgs.). Las consecuencias perversas de la modernidad: modernidad, contingencia y riesgo. Barcelona: Anthropos, 1996.

BREILH, J. Epidemiologia nueva. Buenos Aires: Lugar Editorial, 2004. 
BUCK, C. Popper's philosophy for epidemiologists. International Journal of Epidemiology, n. 4, p. 159-68, 1975.

BUNGE, M. El principio de la causalidad en la ciencia moderna. Buenos Aires: Eudeba, 1969.

CASTELLANOS, P. Avances metodológicos en Epidemiología. IN: CONGRESSO BRASILEIRO DE EPIDEMIOLOGIA., 1. Anais... Campinas, ABRASCO, 1990.

CASTIEL, L. D. Debate sobre o artigo de Almeida-Filho "Transdisciplinaridade e Saúde Coletiva". Ciência e Saúde Coletiva, Rio de Janeiro, v. II, n. 1/2, p. 27-30, 1997.

. O buraco e o avestruz: a singularidade do adoecer humano. Campinas: Papirus, 1994.

CASTORIADIS, C. A instituição imaginária da sociedade. São Paulo: Paz e Terra, 1982.

As encruzilhadas do labirinto. 3 (O Mundo Fragmentado). São Paulo: Paz e Terra, 1992.

CHAUÍ, M. Introdução. Pascal: vida e obra. In: PASCAL. Pensamentos. São Paulo: Nova Cultural. (Col. Os pensadores), 1999.

CHEVAlleY, C. Pascal, contingence et probabilités. Paris: Presses Universitaires de France, 1995.

COSTA, J. F. A face e o verso. Estudos sobre o homoerotismo II. São Paulo: Escuta, 1995.

COSTA, N. Ensaio sobre os fundamentos da Lógica. São Paulo: Hucitec, 1980.

COSTA-CAPRA, R. Fuzzy Logic and Epidemiologic Reasoning. IN: CONGRESSO BRASILEIRO DE EPIDEMIOLOGIA, 3. Resumos... Salvador, ABRASCO, 1995, p. 135.

EDMOND, M.-P. Aristote: la politique des citoyens et la contingence. Paris: Payot, 2000.

ELSTER, J. Ulysses and the sirens. Cambridge: Cambridge University Press, 1984. 
FABIAN, J. Time and the other: how Anthropology makes its object. New York: Columbia University Press, 1983.

FOUCAULT, M. Les mots et les choses: une archéologie des sciences humaines. Paris: Gallimard, 1966.

FREUD, S. El mecanismo psíquico de los fenómenos histéricos (comunicación preliminar). Estudios sobre la histeria. In: Obras completas de Sigmund Freud (Tomo I). Trad. Luis Lopez-Ballesteros y de Torres. Madrid: Biblioteca Nueva, 1973 [1893-5].

GRANDJEAN, P. Implications of the precautionary principle for public health practice and research. Annu Rev Public Health, v. 25, p. 199-223, 2004.

GRENFELL, B.; BOLKER, B.; KLECKOWSKI, A. Seasonality, demography and the dynamics of measles in developed countries. In: MOLLISON, D. (Ed.). Epidemic models: their structure and relation to data. Cambridge: Cambridge University Press, 1995.

HACKING, I. The taming of chance. Cambridge: Cambridge University Press, 1990.

HALLORAN, E.; STRUCHINER, C. Study designs for dependent happenings. Epidemiology, n. 2, p. 331-8, 1991.

HAYES, M. On the epistemology of risk: language, logic and social science. Social Science and Medicine, London, v. 4, n. 35, p. 401-7, 1992.

HEIJENOORT, J. From Frege to Gödel: a source book in mathematical logic, 1879-1931. Massachusetts: Harvard University Press, 1967.

JAPIASSÚ, H.; MARCONDES, D. Dicionário básico de filosofia. Rio de Janeiro: Jorge Zahar, 1990.

JENICEK, M.; CLÉROUX, R. Épidémiologie clinique. Québec: Edisen Inc., 1985.

KOOPMAN, J. Comment: emerging objects and methods in epidemiology. American Journal of Public Health, Washington, v. 5, n. 86, p. 630-2, 1996.

KOOPMAN, J.; LONGINI, I. The ecological effects of individual exposures and nonlinear disease dynamics in populations. American Journal of Public Health, Washington, n. 84, p. 836-42, 1994. 
KRIEGER, N. Epidemiology and the web of causation: has anyone seen the spider? Social Sciences e Medicine, London, v. 7, n. 39, p. 887-903, 1994.

LACAN, J. Séminaire XXI. Les non-dupes errent. (Inédito), 1973-4.

. Situation de la psychanalyse et formation du psychanalyste en 1956.

In: . Écrits. Paris: Seuil, 1966.

LEVY, B. Editorial: Toward a holistic approach to public health surveillance. American Journal of Public Health, Washington, v. 5, n. 86, p. 624-5, 1996.

LILIENFELD, A. Foundations of epidemiology. New York: Oxford University Press, 1976.

LIMA, A. C. Lógica e linguagem. Salvador: EdUFBA, 1993.

LORENZ, E. The essence of chaos. Chicago: University of Chicago Press, 1993.

MACMAHON, B.; PUGH, T. Epidemiology: principles e methods. Boston: Little, Brown and Co, 1970.

MASSAD, E.; STRUCHINER, C. Fuzzy logic and risk assessment in environmental studies. São Paulo, 1996 (mimeo).

MATURANA, H.; VARELA, F. El árbol del conocimiento. Santiago: Editorial Universitaria, 1984.

MCNEILL, D.; FREIBERGER, P. Fuzzy logic. New York: Simon and Schuster, 1993.

MEZZICH, J.; ALMEIDA-FILHO, N. Epidemiology and diagnostic systems in psychiatry. Acta Psychiatrica Scandinavica, Stockholm, n. 90 (suppl. 385), p. 61-5, 1994.

MIETTINEN, O. Theoretical epidemiology. New York: John Wiley and Sons, 1985.

MILNER, J.-C. A obra clara: Lacan, a ciência, a filosofia. Trad. Procópio Abreu. Rio de Janeiro: Jorge Zahar, 1996.

NEWMAN, M.; BARABÁSI, A.-L.; WATTS, D. (Eds.). The structure and dynamics of networks. Princeton: Princeton University Press, 2006.

OAKES, M. Statistical inference. Chestnut Hill: Epidemiologic Resources Inc., 1990. 
OPAS. Riesgos del ambiente humano para la salud. Washington: Oficina Sanitaria Panamericana, 1976. (Publicaciones Científicas, 329).

PASCAL, B. Pensamentos. São Paulo: Nova Cultural. (Col. Os pensadores), 1999.

PERCIVAL, I. Chaos: a science for the real world. In: HALL, N. (Ed.). Exploring chaos. New York: Norton, 1994. p. 11-22.

PHILIPPE, P. Teoria do caos e sistemas complexos em epidemiologia. In: ALMEIDA-FILHO, N. et al. (Eds.). Teoria epidemiológica hoje: fundamentos, tendências, perspectivas. Rio de Janeiro: Abrasco, 1998.

POPPER, K. The logic of scientific discovery. New York: Harper and Row, 1968.

PRIGOGINE, I.; STENGERS, I. La nouvelle alliance. Paris: Gallimard, 1986.

REY, A. Dictionnaire historique de la langue française. Montréal: Dicorobert, 1993.

RORTY, R. Contingency, irony, and solidarity. Cambridge: Cambridge University Press, 1989.

ROTHMAN, K.; GREENLAND, S. Modern epidemiology. Philadelphia: Lippincott-Raven, 1998.

RUELLE, D. Hasard et chaos. Paris: Odile Jacob, 1991.

SADEGH-ZADEH, K. Fuzzy health, illness, and disease. Journal of Medicine and Philosophy, London, v. 5, n. 25, p. 605-38, 2000.

SAMAJA, J. Epistemología y metodología. Buenos Aires: Eudeba, 1994.

SCHRAMM, F.; CASTIEL, L. D. Processo saúde/doença e complexidade em Epidemiologia. Cadernos de Saúde Pública, Rio de Janeiro, v. 4, n. 8, p. 379-90, 1992.

SUSSER, M. Epidemiology, health and society: selected papers. New York: Oxford University Press, 1987.

. The logic in ecological: I. The logic of analysis. American Journal of Public Health, Washington, v. 5, n. 84, p. 825-9, 1994.

SUSSER, M.; SUSSER, E. Choosing a future for epidemiology: I. Eras and paradigms. American Journal of Public Health, Washington, n.86, p.668-73, 1996. 
Choosing a future for epidemiology: II. From black box to Chinese boxes and eco-epidemiology. American Journal of Public Health, Washington, n. 86, p. 674-7, 1996.

THOM, R. Paraboles et catastrophes. Paris: Flammarion, 1985.

VINEIS, P. Nel crepuscolo della probabilità. La medicina tra scienza ed ética. Torino: Einaudi, 1999.

. Prima della malattia: per un'etica della prevenzione. Venecia: Marsilio, 1997.

VON BERTALANFFY, L. General systems theory: a critical review. General Systems, n. 7, p. 1-20, 1962.

WEED, D. On the logic of causal inference. American Journal of Epidemiology, Washington, v. 6, n. 123, p. 965-79, 1986.

ZADEH, L. Toward a theory of fuzzy systems. In: KALMAN, R.; DECLARIS, N. (Eds.). Aspects of network and systems theory. New York: Holt, Rinehart and Winston, 1971.

ZOURABICHVILI, F. Deleuze. Une philosophie de l'événement. Paris: PUF, 1994 (Col. Philosophies).

\section{NOTAS}

- Ph.D. em Epidemiologia. Professor titular de Epidemiologia, Instituto de Saúde Coletiva da UFBA. Pesquisador I-A do Conselho Nacional do Desenvolvimento Científico e Tecnológico. Endereço eletrônico: naomar@ufba.br.

- Psicanalista. Doutora em Letras. Professora adjunta de Metodologia da Pesquisa, Escola de Dança da UFBA. Endereço eletrônico: denisecoutinho@uol.com.br.

1 "Accidens hoc modo sumptum, quod adest et abst sine subjecti corruptione".

${ }^{2}$ Sobre o tema, ver Costa (1995), principalmente o Capítulo I: O sujeito como rede lingüística de crenças e desejos , p. 29-48, onde o autor desenvolve o sintagma "realidades lingüísticas". 
Causalidade, Contingência, Complexidade: o Futuro do Conceito de Risco

\section{ABSTRACT}

\section{Causality, contingency, complexity: the future of the concept of risk}

We contend the thesis that, in the current phase of maturity of the epidemiological field, a reevaluation of the risk concept is timely needed. Initially, we discuss the foundations of categories of causality and contingency in the work of two philosophers, Aristotle and Pascal. Secondly, recovering previous reflections on logical bases of the concept of risk, we critically discuss its explanatory adequacy and efficacy for the health-disease object. Thirdly, we briefly present ground categories and concepts of the complexity paradigm, capable of tackling phenomena of emergency, non-linearity and fuzziness related to new, mutant, complex health objects. We conclude with a few remarks and thoughts yet preliminary on foundations, perspectives and consequences of applying the modality of "contingency" as alternative to notions of determination in the health field, in order to envision the future of the concept of risk far beyond the thematic area (scientific and technological) of contemporary Epidemiology.

Key words: Risk; causality; contingency; complexity; Aristotle. 